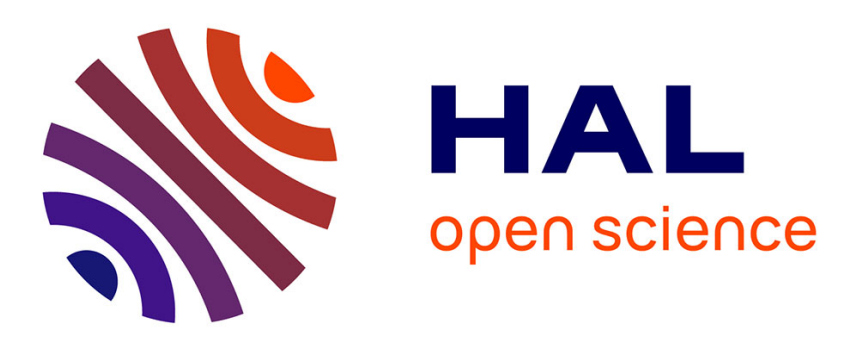

\title{
Modelling vegetation dynamics in managed grasslands: Responses to drivers depend on species richness
}

\author{
Thibault Moulin, Antoine Perasso, François Gillet
}

\section{To cite this version:}

Thibault Moulin, Antoine Perasso, François Gillet. Modelling vegetation dynamics in managed grasslands: Responses to drivers depend on species richness. Ecological Modelling, 2018, 374, pp.22 - 36. 10.1016/j.ecolmodel.2018.02.013 . hal-01779748

\section{HAL Id: hal-01779748 \\ https://hal.science/hal-01779748}

Submitted on 28 Oct 2021

HAL is a multi-disciplinary open access archive for the deposit and dissemination of scientific research documents, whether they are published or not. The documents may come from teaching and research institutions in France or abroad, or from public or private research centers.
L'archive ouverte pluridisciplinaire HAL, est destinée au dépôt et à la diffusion de documents scientifiques de niveau recherche, publiés ou non, émanant des établissements d'enseignement et de recherche français ou étrangers, des laboratoires publics ou privés. 


\section{Abstract}

In mathematical grassland models, plant communities may be represented by a various number of state variables, describing biomass compartments of some dominant species or plant functional types. The size of the initial species pool could have consequences on the outcome of the simulated ecosystem dynamics in terms of grassland productivity, diversity, and stability. This choice could also influence the model sensitivity to forcing parameters. To address these issues, we developed a dynamic grassland model, DYNAGRAM, designed to simulate seasonal changes in both aboveground biomass production and species composition of managed permanent grasslands under various soil, climate and management conditions. We compared simulation results from alternative instances of DYNAGRAM that only differ by the identity and number of state variables describing the green biomass, here plant species. We assessed the sensitivity of each instance of the model to key forcing parameters for climate, soil fertility, and defoliation disturbances, using univariate and multivariate regression trees and dynamic trees.

Results of 10-year simulations under various climate, fertility and defoliation conditions showed that the final total biomass was tending to increase with the size of the species pool, while species evenness and the proportion of surviving species was tending to decrease. We found a positive correlation between the species survival ratio and the defoliation intensity, and this correlation increased with the initial species richness. The sensitivity to forcing parameters of community structure and species evenness differed markedly among alternative models, showing a progressive shift from high importance of soil fertility (fertilisation level, mineralization rate) to high importance of defoliation (mowing frequency, grazing intensity) as the size of the species pool increased. By contrast, the key drivers of total biomass production were independent of species richness and only linked to resource supply (nitrogen and water).

These results highlight the need to take into account the role of species diversity to explain the behaviour of grassland models.

Keywords: dynamic trees; grassland model; multivariate regression trees; plant succession; sensitivity analysis; species pool. 


\section{Introduction}

Semi-natural permanent grasslands present important ecological, cultural and economic values, and support many ecosystem services due to their biodiversity (Gaujour et al., 2012; Mauchamp et al., 2012). Some temperate European grasslands, managed for a long time with low-intensity grazing or mowing, are the plant communities with the world records for species richness at fine scale (Wilson et al., 2012).

Various diachronic studies have revealed recent changes in the structure and composition of grassland plant communities in Europe (Gillet et al., 2016; Homburger and Hofer, 2012; Mitchell et al., 2017; Wesche et al., 2012). The causes of these changes are related to climatic (warming, extreme events) and anthropogenic (technical and socio-economic changes in management) constraints and disturbances. Land-use intensification or abandonment may lead to a severe reduction of species diversity with adverse impacts on ecosystem services. Fertilisation and defoliation regimes have been identified as the main drivers of plant species richness in productive grasslands (Gaujour et al., 2012; Mauchamp et al., 2016, 2014).

According to field observations, local species richness of temperate natural and semi-natural grasslands shows unimodal relationship with productivity, with a maximum biodiversity for intermediate productivity (Dengler et al., 2014). This questions how grassland ecosystem stability and productivity are influenced by vascular plant species richness. Field observations and experiments on semi-natural grasslands suggest that the most productive communities are the least diverse, but also the least resilient. By contrast, field experiments based on artificial species mixtures showed a positive correlation between species richness and productivity (Hector et al., 1999; Reich et al., 2012). A recent meta-analysis of experimental studies on such artificial species assemblages revealed that species richness generally improves resistance of grassland productivity to climatic extreme events, but not its recovery rate (Isbell et al., 2015). Increasing species richness in such artificial communities stabilizes whole community biomass but destabilizes the dynamics of constituent populations (de Mazancourt et al., 2013; Gross et al., 2013).

Since experimental studies have not been able to provide a general explanation to the relationships observed between grassland diversity and their productivity and stability, dynamical models are powerful tools for testing predictions of ecological theories. A lot of mathematical models of grassland dynamics based on explicit ecological processes have been developed. Some non-exhaustive reviews of grassland models are available (Snow et al., 2014; Taubert et al., 2012; Wiegand et al., 2008). Grassland models published so far have targeted monospecific swards (Duru et al., 2009; McCall and Bishop-Hurley, 2003; Schapendonk et al., 1998), mixtures of a grass and a legume species (Lazzarotto et al., 2009; Thornley, 1998), or a multispecies community constant in time (Jouven et al., 2006; Riedo et al., 1998). In a review of thirteen grassland models (Taubert et al., 2012), only two considered more than three different species or plant functional types: GRAS, a succession compartment model (Siehoff et al., 2011) and STEPPE, a gap model of semiarid grasslands (Coffin and Lauenroth, 1990); however, none of them simulate biomass. So far, very few grassland models have been designed to simulate both composition and biomass changes in multispecies semi-natural grasslands used as pastures or/and hayfields, a requirement for understanding diversity-productivity-stability relationships. Indeed, most of current grassland models focus on the impact of agricultural practices on forage production with many ecophysiological and biophysical details inherited from crop models but do not consider temporal changes in taxonomic and functional composition. An attempt (Lauenroth et al., 1993) to couple individual-based gap models describing changes in species composition (STEPPE) and ecosystem models describing nutrient cycling and biomass production (CENTURY) or water balance (SOILWAT) led to the development of the ECOTONE model, 
able to simulate transitions between biomes (Peters, 2002). Several biophysical pasture models can be used to simulate growth of composite pasture types of several species under various management strategies, such as CLASS-PGM, a generic pasture growth model (Vaze et al., 2009), or DAIRYMOD and the SGS Pasture Model (Johnson, 2016), but these models are rather complex, limited to five "species" and not optimized for mowing management. GEMINI (Soussana et al., 2012) is another very detailed biophysical model of grassland ecosystems that explicitly simulates competition among any number of clonal populations for two key resources (light and nitrogen) along vertical canopy and soil profiles; plant functional traits are used to explain the response of aboveground net primary production and of plant community structure to various soil, climate and management conditions, including grazing, cutting and fertilization. Some recent mathematical models are based on stochastic differential equations adapted from the Lotka-Volterra equations to simulate changes in aboveground biomass of plant species mixtures and to explain community dynamics by environmental and demographic stochasticity (de Mazancourt et al., 2013; Lohier et al., 2016).

Taking into account the whole species diversity of grasslands in a mathematical model is quite impossible, given the large number of vascular plant species that may potentially cooccur in such ecosystems. For example, the regional species pool in permanent grasslands of the French Jura Mountains exceeds 1000 and the average number of species per local grassland is about 30, ranging from 3 to 92 (Mauchamp et al., 2012). To reduce the number of state variables describing the plant community in the model, a common solution is to consider plant functional types (PFTs) instead of individual species. PFTs can be viewed as theoretical "average species" combining parameters from a set of more or less functionally related species, such as legumes, perennial grasses or erect forbs. Typically, a PFT is a group of species with similar functional traits explaining their response to constraints and disturbances, such as management practices, and their effect on ecosystem function, such as forage production (Cruz et al., 2010, 2002; Duru et al., 2009; Graux et al., 2016). The GRAS model (Siehoff et al., 2011) simulates the succession of both dominant species and PFTs described by their cover dynamics, contrary to most agronomic grassland models, such as MODVEGE (Calanca et al., 2016; Jouven et al., 2006), which simulate seasonal changes in one or several biomass compartments, assuming a constant assemblage of species or PFTs. Individual-based, spatially explicit community grassland models such as IBC-GRASS (Weiss et al., 2014) are able to simulate metacommunities of many PFTs over hundred years, but at the price of a simplified representation of edaphic and climatic drivers. By contrast, (Confalonieri, 2014) suggested a model of plant community dynamics based on a single instance of a generic crop simulator, state variables being only simulated for the whole community. ECOHYD (Lohmann et al., 2017) is an ecohydrological model of semi-arid grasslands and savannas, able to simulate cover dynamics of a large number of PFTs, but focuses on hydrological processes and does not implement nutrient stress.

In this paper, we address a general issue that could be raised in any modelling study: the appropriate choice of the level of detail of the model, i.e. the number of state variables and associated parameters to be taken into account for describing the dynamical system, here the plant community. Although this choice is usually motivated by model objectives (e.g., with a focus on forage production or on biodiversity conservation) and by technical constraints (e.g., data availability, model performance), what are its consequences on the simulated dynamics of the virtual community in terms of grassland productivity, diversity, and stability? This question is especially relevant for permanent grasslands used for grazing or mowing and subject to seasonal changes in species composition and forage production, because of the high number of species coexisting in such ecosystems.

Thus, the first aim of the present study is to examine the consequences of increasing the number of state variables (i.e. the size of the local species pool) describing plant community 
composition on model behaviour, regarding grassland productivity, diversity and stability. Specifically, we formulated four hypotheses: (H1) the inclusion of more species in the model increases its productivity, hence the final total biomass after ten-year simulations with various values of control parameters; (H2) the inclusion of more species in the model decreases its final species evenness, the component of community diversity measuring equitability in biomass and resource partitioning among species; (H3) the inclusion of more species in the model decreases its stability, hence the final proportion of surviving species (species survival ratio); (H4) species survival ratio increases with intensity and frequency of disturbances, and this positive correlation increases with the size of the species pool.

The second purpose is to assess the consequences of increasing the size of the species pool on the model sensitivity to key control parameters regarding climate, soil fertility and defoliation. We hypothesized that (H5) the hierarchy of influential parameters depends on species identity but not on the size of the species pool.

For these purposes, we need a simple mechanistic model in which the main ecological processes are implemented (seasonal mechanisms of plant growth, soil resource competition, response to climatic constraints and agricultural management) and in which we can vary the number and the identity of species in the initial plant community. As no such model was available, we developed DYNAGRAM, a simple and flexible dynamical model based on ordinary differential equations (ODEs), able to simulate various combinations of climate, soil and management conditions. The aim of this paper is not to present this model in detail along with results of calibration and validation with experimental data, which will be the topic of a next paper, but to use it as a tool to address two general relevant questions in ecological modelling. We simply ensured we properly modelled competition processes among species, under various forms of land use, by comparing simulated results to expert knowledge of

168 grassland ecosystems (Cruz et al., 2010).

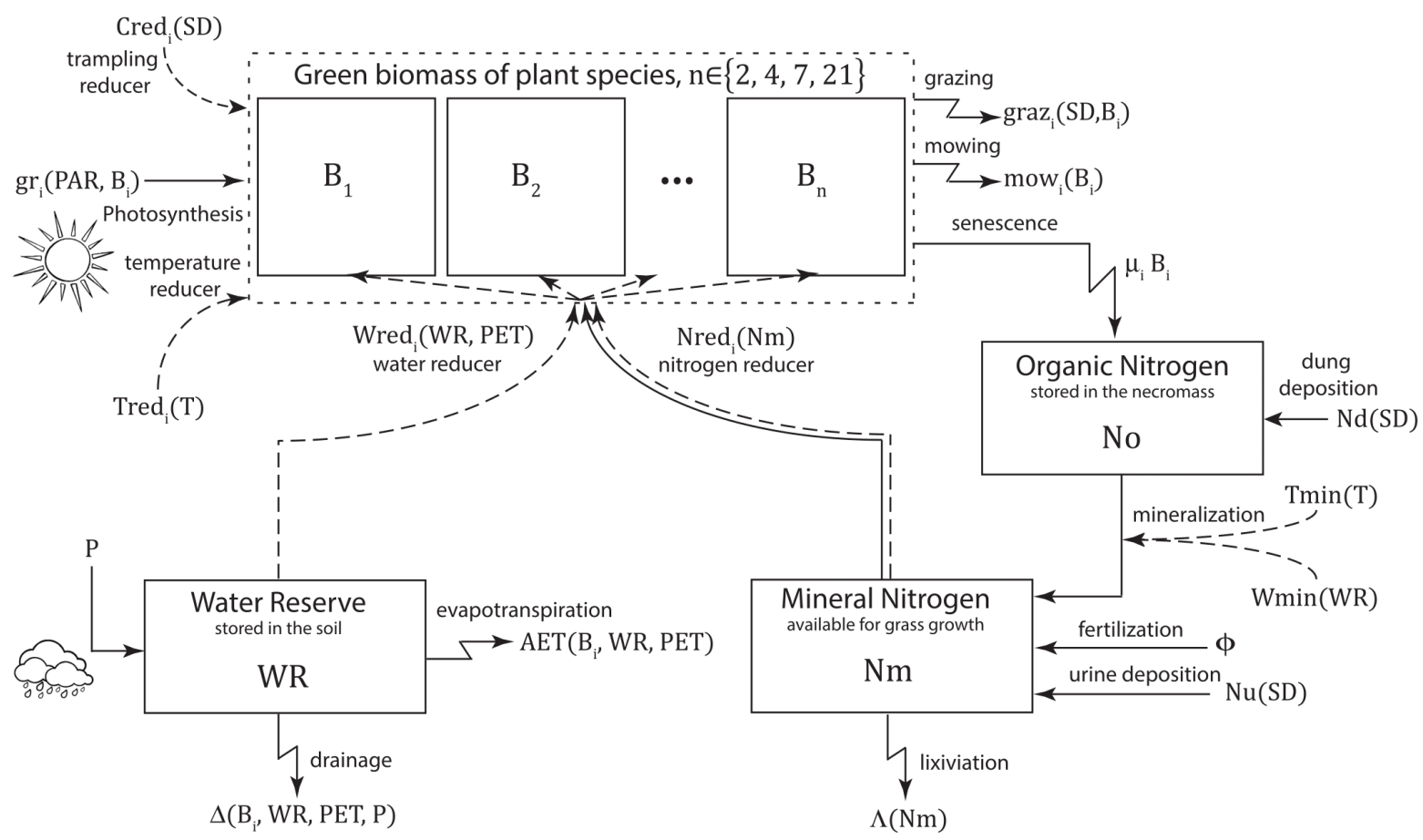

Fig. 1 Structure of the DYNAGRAM model. Solid lines denote flows of matter or energy and dashed lines denote reducers (mineral nitrogen acts both as a flow and as a reducer). State variables and forcing climatic variables are listed in Table 1 and a description of all parameters can be found in Tables A.1 and A.2 (Appendix A). 


\section{Materials and methods}

\subsection{Model structure and main assumptions}

177 DYNAGRAM is a process-based succession model that simulates the aboveground vegetation dynamics of a temperate grassland, both in term of composition and of forage production. Using a common structure (Fig. 1), we developed four alternative versions of the model, which correspond to different levels of diversity.

We built DYNAGRAM under some key assumptions, in the way to capture only essential processes, and keeping as reduced as possible the dimension of the parameter space. Grassland vegetation is described by $n$ state variables $B_{i}$ representing the green biomass (leaves) for each plant species $i$. We did not consider the belowground biomass (roots) and the reproductive parts of the plants. Hence, we assumed no seed production and no recruitment from the seedbank. Two other state variables describe available resources in the soil: mineral nitrogen $\mathrm{Nm}$ and water reserve $W R$ (Table 1).

Basically, DYNAGRAM is a mechanistic model of resource competition (Tilman, 1980) operating at a daily time step. We mainly based the regulation of green biomass and plant competition from the standpoint of resource dynamics. A single nutrient, mineral nitrogen (nitrate or ammonium), is consumed by plants for growth and is supplied by a pool of soil organic nitrogen $\mathrm{No}$, itself supplied by the senescence of standing biomass and litter decomposition.

We considered four forcing climatic variables defined as simple sinusoidal functions of time and acting on different processes (Table 1). This simplified formulation of the annual cycle allows the manipulation of a reduced number of climatic parameters. Average daily temperature $T$ acts as a limiting factor for plant growth and litter decomposition, daily rainfall $P$ fills the soil water reserve, photosynthetic active radiation $P A R$ is a driver of biomass production by photosynthesis, and potential evapotranspiration PET determines the loss term in the soil water budget equation that may cause drought stress.

Table 1 State variables and forcing climatic variables implemented in DYNAGRAM.

\begin{tabular}{lll}
\hline $\begin{array}{l}\text { State } \\
\text { variables }\end{array}$ & Symbol & Description \\
\hline $\begin{array}{l}\text { Green } \\
\text { biomass }\end{array}$ & $B_{i}$ & $\begin{array}{l}\text { Green biomass of } \\
\text { plant species } i\end{array}$ \\
\hline $\begin{array}{l}\text { Organic } \\
\text { nitrogen }\end{array}$ & $N o$ & $\begin{array}{l}\text { Amount of } \\
\text { organic nitrogen } \\
\text { in the soil }\end{array}$ \\
\hline $\begin{array}{l}\text { Mineral } \\
\text { nitrogen }\end{array}$ & $N m$ & $\begin{array}{l}\text { Amount of } \\
\text { mineral nitrogen } \\
\text { in the soil } \\
\text { available for } \\
\text { plant growth }\end{array}$ \\
& & $\begin{array}{l}\text { Amount of water } \\
\text { in the soil } \\
\text { available for the } \\
\text { plants }\end{array}$ \\
\hline $\begin{array}{l}\text { Water } \\
\text { reserve }\end{array}$ & $W R$ & \\
\hline
\end{tabular}

\begin{tabular}{lll}
$\begin{array}{l}\text { Forcing climatic } \\
\text { variables }\end{array}$ & Symbol & Description \\
\hline Temperature & $T$ & $\begin{array}{l}\text { Daily average air } \\
\text { temperature acting on } \\
\text { plant growth and } \\
\text { mineralization rates }\end{array}$ \\
\hline Precipitation & $P$ & $\begin{array}{l}\text { Daily rainfall, the } \\
\text { supply to the water } \\
\text { reserve }\end{array}$ \\
\hline $\begin{array}{l}\text { Photosynthetically } \\
\text { active radiation }\end{array}$ & $P A R$ & $\begin{array}{l}\text { Portion of the solar } \\
\text { radiation spectrum } \\
\text { driving photosynthesis } \\
\text { and determining } \\
\text { potential growth }\end{array}$ \\
& & $\begin{array}{l}\text { Function that } \\
\text { determines the loss } \\
\text { term in the water } \\
\text { budget }\end{array}$ \\
\hline $\begin{array}{l}\text { Potential } \\
\text { evapotranspiration }\end{array}$ & $P E T$ &
\end{tabular}


Green biomass dynamics for each species is described by the following ODE (1). For clarity reason, we only wrote the dependence on state variables:

$$
\begin{gathered}
\frac{d B_{i}}{d t}=\operatorname{gr}_{i}\left(B_{i}\right) \operatorname{Nred}_{i}(N m) \operatorname{Tred}_{i} \operatorname{Wred}_{i}(W R) \operatorname{Cred}_{i}-\mu_{i} B_{i}-\operatorname{mow}_{i}\left(B_{i}\right) \\
-\operatorname{graz}_{i}\left(B_{i}\right)
\end{gathered}
$$

where $\mu_{i}$ is a constant leaf senescence rate, as assumed in the GRAS model (Siehoff et al., 2011). A comprehensive description of DYNAGRAM will be the subject of a next paper. Below we provide details on the three functions $g r_{i}$, mow $w_{i}$ and $g r a z i$, useful to better understand the sensitivity analysis we performed. A complete description of all parameters is given in Tables A.1 and A.2 (Appendix A).

We assumed plant growth $g r_{i}\left(P A R, B_{i}\right)$ to be driven by an Ivlev function describing the photosynthesis process, as defined in ModVEGE (Jouven et al., 2006) and in LiNGRA (Schapendonk et al., 1998). This function defines the maximal growth obtained in optimum conditions regarding resources (nutrients, water) and temperature, and in absence of disturbances (trampling). It describes the efficiency of use of solar radiation for photosynthesis and is modelled as the product of the Photosynthetically Active Radiation $(P A R)$, the maximal Radiation Use Efficiency $(R U E)$, which accounts for a decrease in efficiency at light intensity higher than $5 \mathrm{MJ} \mathrm{m}^{-2}$, and an Ivlev function of the Surface Leaf Area $\left(S L A_{i}\right)$ and of the plant biomass $\left(B_{i}\right)$ that accounts for the proportion of light intercepted by the sward. This optimum plant growth function is given by equation (2).

$$
\begin{aligned}
& g r_{i}\left(P A R(t), B_{i}(t)\right)=\operatorname{PAR}(t) R U E(t)\left(1-e^{-\alpha S L A_{i} \frac{B_{i}(t)}{10} L A M}\right) 10, \\
& R U E(t)=R U E_{\text {max }} \min \left(1,1-\gamma_{1}\left(P A R(t)-\gamma_{2}\right)\right)
\end{aligned}
$$

Four reducers decrease biomass productivity. The first reducer, $\operatorname{Nred}_{i}(\mathrm{Nm})$, is modelled by an Holling function depending on the biomass. The second reducer, $\operatorname{Wred}_{i}(W R, P E T)$, is a function of the water reserve and of the potential evapotranspiration. The third growth reducer, $\operatorname{Tred}_{i}(T)$, depends on temperature. The fourth reducer, $\operatorname{Cred}_{i}(S D)$, represents a decrease in plant growth due to trampling and is function of the livestock density, $S D$. Defoliation disturbances, i.e. mowing $\operatorname{mow}_{i}\left(B_{i}\right)$ and grazing $\operatorname{graz}_{i}\left(S D, B_{i}\right)$, act as a loss in green biomass.

The first defoliation disturbance consists on mowing events with a periodical cut of the canopy, following a pre-specified mowing schedule. All $B_{i}$ variables related to green biomass are pulse-wise reduced and a proportion $\lambda_{i}$ of all species biomass is removed. We assume this proportion to be independent of the biomass value and only depends on the species-specific canopy height. For a given mowing event, we get:

$$
\operatorname{mow}_{i}\left(B_{i}(t)\right)=\lambda_{i} B_{i}(t)
$$

The second defoliation disturbance is due to grazing by livestock, following a predefined schedule. At every grazing day, a fixed amount $\kappa S D$ of standing biomass is removed by grazing. This loss of biomass is distributed among all species according to their appetence and their biomass, following a Holling type III function. During a given grazing period, we get:

$$
\operatorname{graz}_{i}\left(S D(t), B_{i}(t)\right)=\kappa S D(t) \frac{\rho_{i} B_{i}^{n g}(t)}{1+\sum_{j=1}^{n} \rho_{j} B_{j}^{n g}(t)}
$$

Soil processes are summarised by the following ODEs (5) to (7). Again, we only wrote the dependence on state variables.

$$
\frac{d N o}{d t}=\sum_{i=1}^{n} \delta_{i} \mu_{i} B_{i}+N d-\theta N o T \min W \min (W R)
$$




$$
\begin{aligned}
\frac{d N m}{d t}= & \theta \text { No Tmin } W \min (W R)+N u+\Phi-\Lambda(N m) \\
& \quad-\sum_{i=1}^{n} \delta_{i} \operatorname{gr}_{i}\left(B_{i}\right) \operatorname{Nred}_{i}(N m) \operatorname{Tred}_{i} \operatorname{Wred}_{i}(W R) \text { Cred }_{i}
\end{aligned}
$$

We introduced feedback loops for the two resources, available nitrogen and water reserve in the soil. The loss of green biomass due to senescence constitutes the litter, which fills a pool of organic nitrogen No stored in the soil organic matter. Depending on surface temperature $\operatorname{Tmin}(T)$ and soil moisture $W \min (W R)$, this organic nitrogen is mineralized in mineral nitrogen $\mathrm{Nm}$ (nitrate and ammonium) that becomes available for plant uptake. These two reducer functions affect the mineralization process and should not be confused with Tred and Wred that reduce plant growth. For each unit of biomass produced, we assumed that a fixed proportion $\delta_{i}$ of mineral nitrogen is consumed (Lazzarotto et al., 2009). Lixiviation $\Lambda(\mathrm{Nm})$ limits the amount of mineral nitrogen in the soil solution. Presence of grazing animals in the pasture brings organic $N d(S D)$ and mineral $N u(S D)$ nitrogen restitution proportionally to the stock density $S D$. The mineral nitrogen pool is also filled by mineral fertilization events, $\Phi$. The water reserve $W R$ is filled by precipitations $P$ and is emptied by the actual evapotranspiration $A E T\left(B_{i}, W R, P E T\right)$ and by drainage $\Delta\left(B_{i}, W R, P E T, P\right)$. AET corresponds to the amount of water lost daily by evapotranspiration, which depends on green biomass, water reserve $W R$ and potential evapotranspiration PET. Drainage corresponds to the loss of water by infiltration once the water reserve in the soil exceeds the water holding capacity WHC.

To summarize, if $n$ is the size of the species pool, DYNAGRAM is defined by a system of $3+$ $n$ ordinary differential equations associated with $3+n$ state variables, with $9 \times n$ speciesspecific parameters, 31 global parameters, and 13 parameters for climatic forcing functions. The three primary C-S-R plant strategies defined by Grime (Grime, 1977; Pierce et al., 2017) are implicitly included in DYNAGRAM. Competitive ability (C strategy) occurs without any stress or disturbance and mainly depends on the potential growth rate of each species and their efficiency to achieve photosynthesis (parameters $S L A_{i}, \mu_{i}$ ). Stress tolerance ( $\mathrm{S}$ strategy) is represented by several species-specific parameters included in the reducers of this potential vegetative growth regarding three limiting factors (temperature, mineral nitrogen and water) and a trampling effect (parameters $T_{1, i}, k_{i}, \eta_{i}, \sigma_{i}$ ). Resistance to disturbance (R strategy) is represented by species-specific parameters concerning resistance to defoliation (mowing and grazing, which correspond to an explicit loss in green biomass; parameters $\rho_{i}, \lambda_{i}$ ). To show the wide diversity of life strategies and plant functional types among the 21 species considered in DYNAGRAM, we plotted their location within the CSR triangle in Fig. 2.

The DYNAGRAM model complies with five out of six criteria introduced in a recent review of grassland models (Taubert et al., 2012), by taking into account: (1) species richness, (2) resource limitation (light, nutrients, water), (3) management activities (mowing, grazing, fertilizing), (4) model simplicity, and (5) interspecific competition for resources. To keep the model simple, we did not comply with the sixth criterion concerning the representation of belowground competition processes.

We implemented DYNAGRAM in R language (R Core Team, 2017). Numerical integration of the ODE system was computed with the function 'ode()' of the R package 'deSolve' (Soetaert et al., 2010), using the Euler method and an integration time step of one day to correspond to the length of discrete management events included in the model. This choice of discrete time and difference equations was also made to reduce the simulation time in batch runs, after 
having verified that the model outputs were similar to the ones obtained with a smaller fixed or variable time step and a solver considering continuous time, such as 'lsoda', taking into

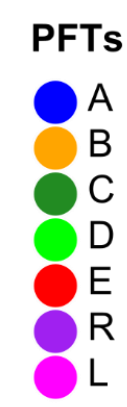

\subsection{Choice of the biomass state variables}

As our aim was to capture the dynamics of the taxonomic and functional community composition and to assess the importance of community diversity, we considered various combinations of species to represent biomass state variables. In this way, we wrote four alternative versions of DYNAGRAM that only differ by the number $n \in\{2,4,7,21\}$ of these state variables. We designed several assemblages containing a number $n$ of species selected as follows among a list of 21 representative herbaceous species (Table A.2 in Appendix A). A first model version (DYNAGRAM2) considers a mixture of two species, namely perennial ryegrass (Lolium perenne), a grass, and white clover (Trifolium repens), a legume. These two species are frequent in intensively managed grasslands and are included in several agronomic grassland models, such as PROGRASS (Lazzarotto et al., 2009), which derives from the pasture simulation model PASIM (Calanca et al., 2007; Graux et al., 2011; Riedo et al., 1998). We selected a set of frequent and potentially dominant individual species, differing by their functional traits and ecological preferences, representative of the species pool in midmountain European pastures and hayfields to be included in a second version of the model 
(DYNAGraM21) with 21 plant species. As shown by Fig. 2, these species belong to various

308 PFTs and present a wide range of CSR strategies.

309 Finally, for DYNAGRAM4 and DYNAGRAM7, we kept the two species present in

310 DYNAGRAM2 (Lolium perenne and Trifolium repens), to which we added ten combinations of two or five other species, respectively, randomly selected among the 19 remaining species included in DYNAGRAM21. Thus, by keeping in all 22 alternative instances of the model (the basic DYNAGRAM2, the full DYNAGRAM21, and ten replicates of DYNAGRAM4 and DYNAGRAM7) a same grass and a same legume species we ensured a minimum common heterogeneity in the functional composition of each instance, and by our random selection of other species we avoided any subjective bias.

\subsection{Selection of the key control parameters}

When performing a sensitivity analysis, we look at the sensitivity of a model output $\mathbf{Y}=f(\mathbf{X})$ to variations of the control parameters in a matrix $\mathbf{X}$. Each line of the matrix $\mathbf{X}$ defines a set of parameters for which we solve the ODE system. In a first identification analysis, we assessed the sensitivity of model outputs (total biomass and species evenness) to a deviation of $\pm 20 \%$ of all parameters, except species-specific parameters (Online Appendix B, Tables B.1, B.2 and B.3).

From the results of this first analysis, we selected the six most influential control parameters to be used for a more detailed sensitivity analysis, grouped in three categories: (i) climate parameters include mean monthly temperature $T m$ and mean monthly sum of precipitation $P m$; (ii) soil fertility parameters include the mineralization rate of organic nitrogen $\theta$ and the amount of mineral nitrogen dropped off each year on the soil as fertilizers $\Phi$; (iii) defoliation disturbance parameters include the livestock density $S D$ during each grazing period and the number of mowing events per year $n c u t$. The $\mathbf{X}$ matrix consisted of all 1728 combinations of three or four values for the six control parameters (Table 2).

We considered a management scenario that is identically repeated each year. Cattle is continuously present in the grassland during one long grazing season, from the $1^{\text {st }}$ of July to the $31^{\text {st }}$ of August. The first mowing event appears on the $1^{\text {st }}$ of June, and a second mowing event on the $2^{\text {nd }}$ of October. The amount of fertilizer, $\Phi=90 \mathrm{~kg} \mathrm{~N} \mathrm{ha}^{-1}$, is split in six fractions spread on the grassland (May $1^{\text {st }}$, May $15^{\text {th }}$, June $10^{\text {th }}$, June $20^{\text {th }}$, September $1^{\text {st }}$ and September $\left.15^{\text {th }}\right)$.

Table 2 Set of values of the selected control parameters in the matrix $\mathbf{X}$ of the sensitivity analysis. those values, leading to $3^{3} \times 4^{3}=1728$ lines. LU: livestock unit ( $1 \mathrm{LU}$ is equivalent to a dairy cow).

\begin{tabular}{|c|c|c|c|c|c|c|}
\hline Parameter & Category & & Value & $\mathrm{x} \mathbf{X}$ & & Unit \\
\hline $\mathrm{Tm}$ & Climate & 7 & 9 & 11 & & ${ }^{\circ} \mathrm{C}$ \\
\hline Pm & Climate & 50 & 80 & 110 & 140 & $\mathrm{~mm}$ month $^{-1}$ \\
\hline$\theta$ & Soil fertility & $410^{-4}$ & $710^{-4}$ & $110^{-3}$ & & $\mathrm{~d}^{-1}$ \\
\hline$\Phi$ & Soil fertility & 0 & 20 & 50 & 100 & $\mathrm{~kg} \mathrm{~N} \mathrm{ha}^{-1} \mathrm{a}^{-1}$ \\
\hline$S D$ & Defoliation & 0 & 0.5 & 1 & 1.5 & $\mathrm{LU}_{\text {ha }}{ }^{-1}$ \\
\hline ncut & Defoliation & 0 & 1 & 2 & & $a^{-1}$ \\
\hline
\end{tabular}


The next step was thus to extract the response variables from the simulation outputs after running each alternative version of the model. Those response variables are either a matrix $\mathbf{Y}$ (if built from several output variables per simulation) or a vector $\mathbf{y}$ (if built from a single output variable).

Each line of the input matrix $\mathbf{X}$ corresponds to a set of parameters, for which we run the model and generated one response matrix $\mathbf{Y}$ and three response vectors $\mathbf{y}$ extracted from the model output at time $t_{f}=3559$, that is the $1^{\text {st }}$ of October at year 10 of the simulation. This day is selected just before the second yearly cut and after all other management practices having occurred in the year.

$\mathbf{Y}$ is a $n$-columns matrix of biomass values of all species at day $t_{f} . \mathbf{y}_{1}$ is a vector of the total biomass values $B_{t o t}$ at day $t_{f}$, simply computed as the sum of the green biomass values of all present species:

$$
B_{t o t}\left(t_{f}\right)=\sum_{i=1}^{n} B_{i}\left(t_{f}\right)
$$

357

358

359

360

361

362

363

364

365

366

$\mathbf{y}_{2}$ is a vector of Simpson evenness values $B_{\text {eve }}$ of the plant community at day $t_{f}$. Simpson evenness is a taxonomic diversity index ranging between 0 and 1 and measuring the proportion of dominant species in the community according to differences in biomass (Hill, 1973; Jost, 2006). A value of 1 means that all species initially introduced are equally distributed in biomass in the grassland, whereas a value close to 0 means the persistence of only one single species that outcompeted all others. We computed Simpson evenness by dividing the inverse Simpson diversity index by $n$, the number of species initially present in the model:

$$
B_{\text {eve }}\left(t_{f}\right)=\frac{1}{n \sum_{i=1}^{n}\left(\frac{B_{i}\left(t_{f}\right)}{B_{\text {tot }}\left(t_{f}\right)}\right)^{2}}
$$

$\mathbf{y}_{3}$ is a vector of the ratio $S$ of the number of surviving species at day $t_{f}$ to the initial species pool $n$, considering as virtually absent a species with a biomass less than $1 \mathrm{~g} \mathrm{DM} \mathrm{ha}^{-1}$ :

$$
S\left(t_{f}\right)=\frac{\#\left\{B_{i}\left(t_{f}\right)>10^{-3}\right\}}{n}
$$

$$
S \text { represents the final proportion of surviving species, also called 'species survival ratio' }
$$
thereafter.

\subsection{Assessment of the model's response to variation in species richness}

To relate the variation of the computed indexes $B_{t o t}, B_{\text {eve }}$ and $S$ to the size of the initial species pool, we performed Kruskal-Wallis tests with post-hoc multiple comparisons on the simulation outputs over all combinations of values for the six climate, fertility and defoliation parameters. Differences in total final biomass $B_{\text {tot }}$ would allow to know if grassland productivity is impacted by increasing species richness in the model, whereas differences in evenness $B_{\text {eve }}$ and survival species $S$ would provide information about the impact on community diversity and resilience.

\subsection{Tree-based sensitivity analysis}

Regression tree is an iterative process of dividing the data into two partitions, and then splitting it up further on each of the branches using discriminant explanatory variables (De'ath and Fabricius, 2000). Each split corresponds to a node. A regression tree can be interpreted as 
a decision tree, in which terminal leaves group records with homogenous response variables that can be explained by a series of explanatory variables (here model parameters). The homogeneity of each node is characterized by its impurity, a measure that takes the value zero for completely homogeneous nodes and increases as homogeneity decreases. Then maximizing homogeneity in a given group is equivalent to minimizing their impurity. The predicted value of the output variable for a particular node is the sample average of the output variable consisting of records included in that node. The splitting process continues until each node reaches a user-specified minimum node size and becomes a terminal node (Makler-Pick et al., 2011).

Dynamic trees were introduced to provide Bayesian inference for regression trees that change with the arrival of new observations (Taddy et al., 2011). Dynamic trees provide an efficient measure of a covariate's first-order effect, i.e. variance reduction directly attributed to splits on that variable. However, these indices are not appropriate for all applications of sensitivity analysis, as non-constant leaf prediction models, such as for linear trees. This issue has been corrected by a technique of estimation of sensitivity indices (Gramacy et al., 2013), which is model-free and can be constrained to subsets of the input space. Thus, DT computes the Sobol index associated to the sensitivity analysis (Ravalico et al., 2005), and graphically estimates how each parameter from the set of the matrix $\mathbf{X}$ impacts the output variable in vector $\mathbf{y}$.

To investigate the influence of the number of state variables describing the plant community (aboveground biomass of individual species) on the model sensitivity to key parameters (climate, soil fertility, defoliation), we performed a tree-based sensitivity analysis for each level of complexity of DYNAGRAM, with 2, 4, 7 and 21 species, based on the matrix $\mathbf{X}$ and $\mathbf{Y}$ (or vector $\mathbf{y}$ ) described previously.

Our sensitivity analysis was based on three kinds of trees: (i) Univariate Regression Tree (URT); (ii) Multivariate Regression Tree (MRT) and (iii) Dynamic Tree (DT). URT and DT consider a vector $\mathbf{y}$ containing one single synthetic variable $\left(B_{t o t}, B_{\text {eve }}\right.$, or $\left.S\right)$ contrary to MRT (De'ath, 2002) that considers a matrix Y including several response variables (biomass of each species). URT has been used to rank a set of influential control parameters, here $\{\mathrm{Tm}$, $P m, \theta, \Phi, S D, n c u t\}$, from top to bottom, according to their impact on a single output variable among the set $\left\{B_{t o t}, B_{\text {eve }} S\right\}$ for performing global sensitivity analysis (Eynaud et al., 2012; Makler-Pick et al., 2011).

We applied URT and DT to assess the sensitivity of the three response variables (total biomass $B_{t o t}$, Simpson evenness $B_{\text {eve }}$ and survival rate $S$ at time $t_{f}$ ) to the variation of the six control parameters in matrix $\mathbf{X}$.

To assess the sensitivity of species composition to the variation of the same parameters we applied MRT to the multivariate response matrix $\mathbf{Y}$ of all species biomasses, constrained by the input parameter matrix $\mathbf{X}$. To our knowledge, it is the first application of MRT to model sensitivity analysis.

We pruned each tree to plot the result with six terminal nodes. We determined the most influential parameters selected by univariate and multivariate regression trees by retaining the three discriminant parameters up to the second splits of each URT or MRT, respectively. We compared the average number of discriminant parameters of each category (climate, soil fertility or defoliation) among the four species richness levels (2, 4, 7 and 21).

All analyses were performed in the R environment (R Core Team, 2017) with the packages 'mvpart' (univariate and multivariate regression trees) and 'dynaTree' (dynamic trees). 


\section{Results}

\subsection{Model response to variation in initial species richness}

428 Under various climate, fertility and defoliation conditions given by all combinations of the six 429 control parameters, the final total biomass after ten years of simulation $B_{t o t}$ globally increased 430 with the number of species in the grassland (Fig. 3A).

431 By contrast, Simpson evenness $B_{\text {eve }}$ tended to decrease with initial species richness, showing 432 that the more the species pool was large, the less the final green biomass was equally 433 distributed among the species (Fig. 3B).

434 The proportion of surviving species $S$ tended also to decrease with the size of the species pool 435 (Fig. 3C). However, for any initial species richness, we observed that some combinations of parameter values led to cases with null values for each response variable, i.e. with the

438 For 21 species in the initial species pool, the survival rate increased with the disturbance 439 intensity, which is the product of defoliation parameters $S D$ and $n c u t$ (Fig. 4A). Moreover, the 440 positive Kendall rank correlation between the disturbance intensity and the species survival 441 rate increased with the size of the species pool (Fig. 4B).

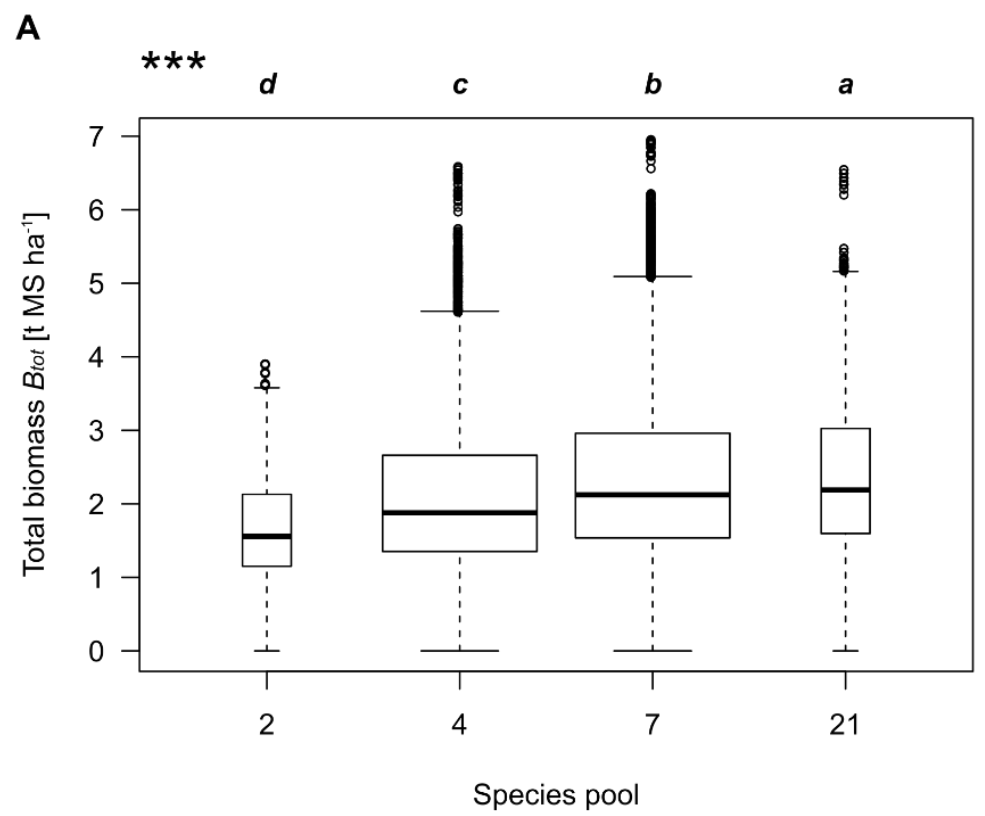


B

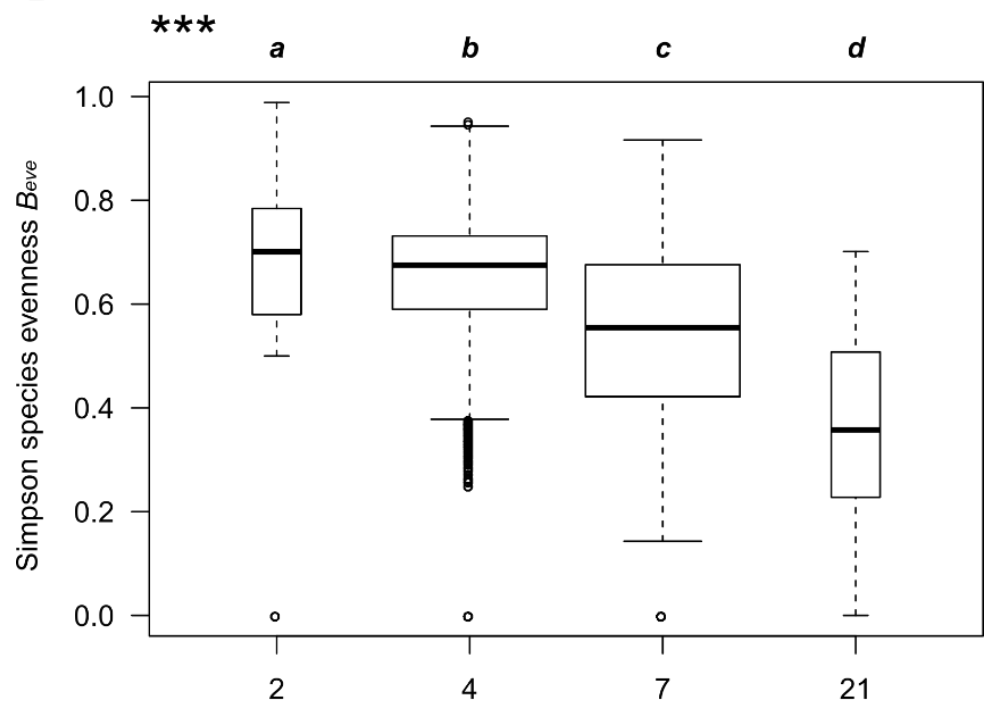

Species pool

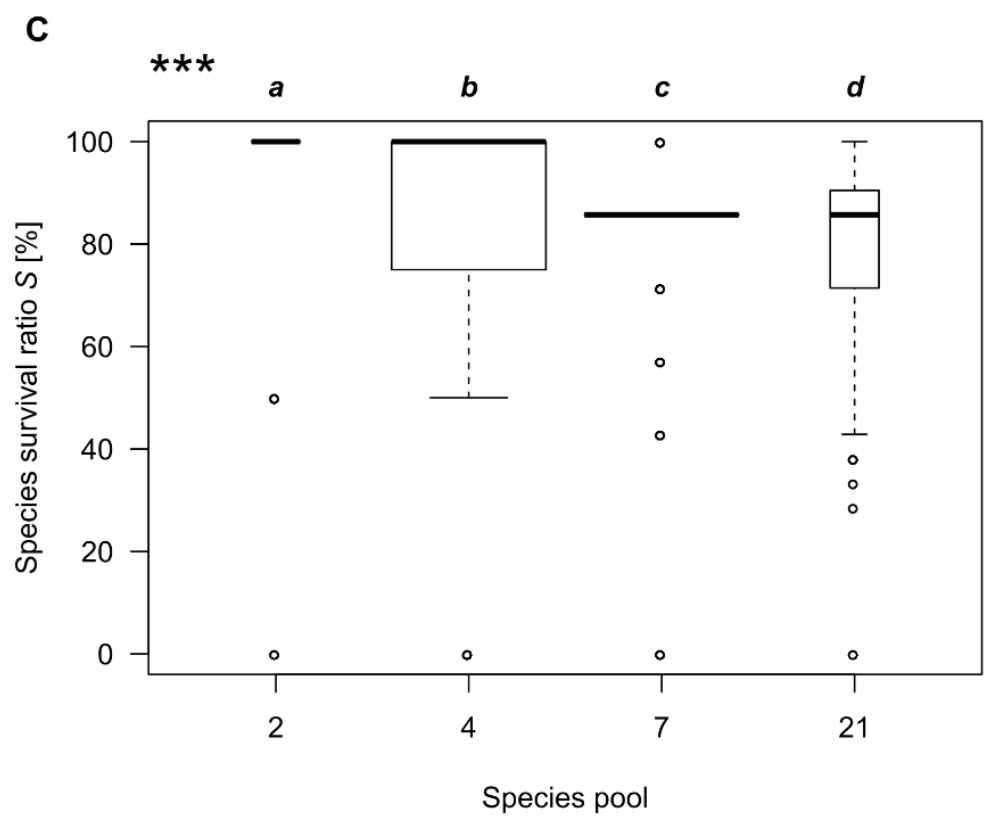

445 Fig. 3 Boxplots of final total biomass $B_{\text {tot }}(\mathbf{A})$, Simpson species evenness $B_{\text {eve }}(\mathbf{B})$ and proportion of surviving species $S(\mathbf{C})$ at the end of simulations from alternative DYNAGRAM models with all combinations of control parameters given in Table 2. All results of Kruskal-Wallis tests were highly significant (***: $P<0.001$ ). Different letters indicate significant differences among groups of simulations, based on 1728 simulations for 2 and 21 species, and 10 series of 1728 simulations for different assemblages of 4 and 7 species. 


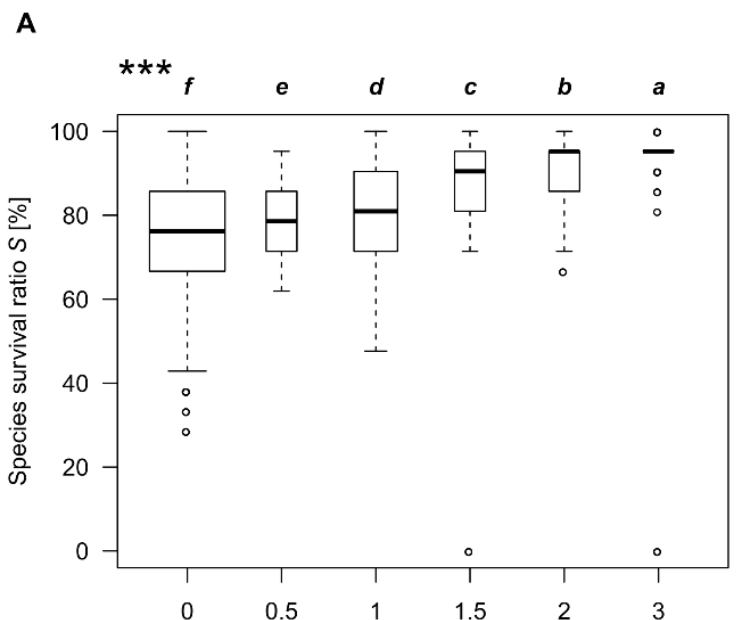

Defoliation intensity $S D^{*} n c u t$
B

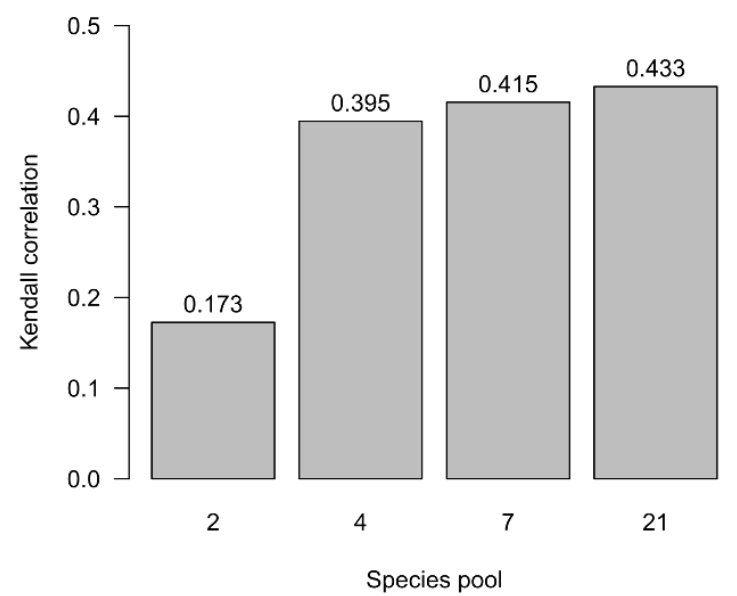

452

453

454

455

456

457

458

459

460

461

462

463

464

465

A

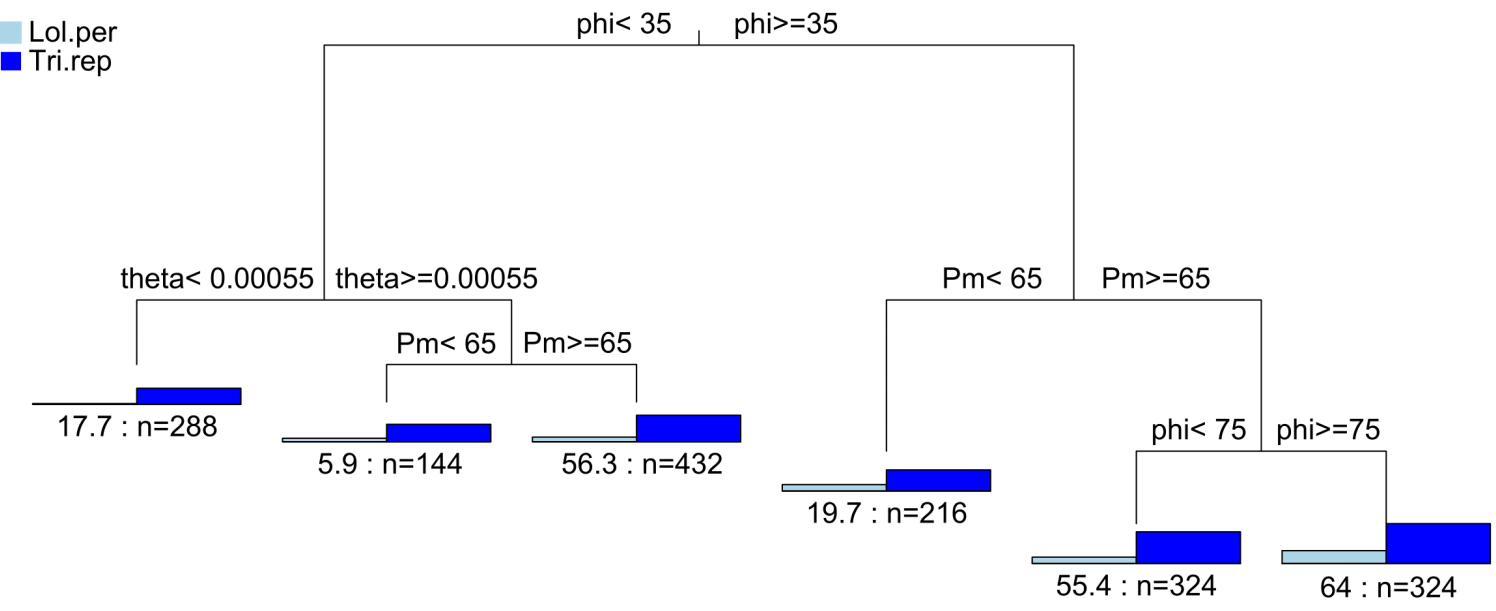

Error : 0.374 CV Error : 0.383 SE : 0.0109

Fig. 4 The relationship between the defoliation intensity and the species survival ratio. A: Boxplots of the proportion of surviving species $S$ at the end of simulations from DYNAGRAM21 with all combinations of control parameters, in function of the level of defoliation intensity, with results of Kruskal-Wallis and post-hoc tests $(* * *: P<0.001)$; different letters indicate significant differences among levels, based on 1728 simulations for 21 species. B: Bar plot of the Kendall rank correlations between the size of the species pool $n$ and the species survival ratio $S$, based on 1728 simulations for 2 and 21 species, and 10 series of 1728 simulations for different assemblages of 4 and 7 species.

\subsection{Sensitivity analysis of DYNAGRAM for 2 and 21 species}

To illustrate some details of the sensitivity analysis we performed, let us focus at first on the results of simulations with the extreme values of the species pool, i.e. 2 and 21 species. 


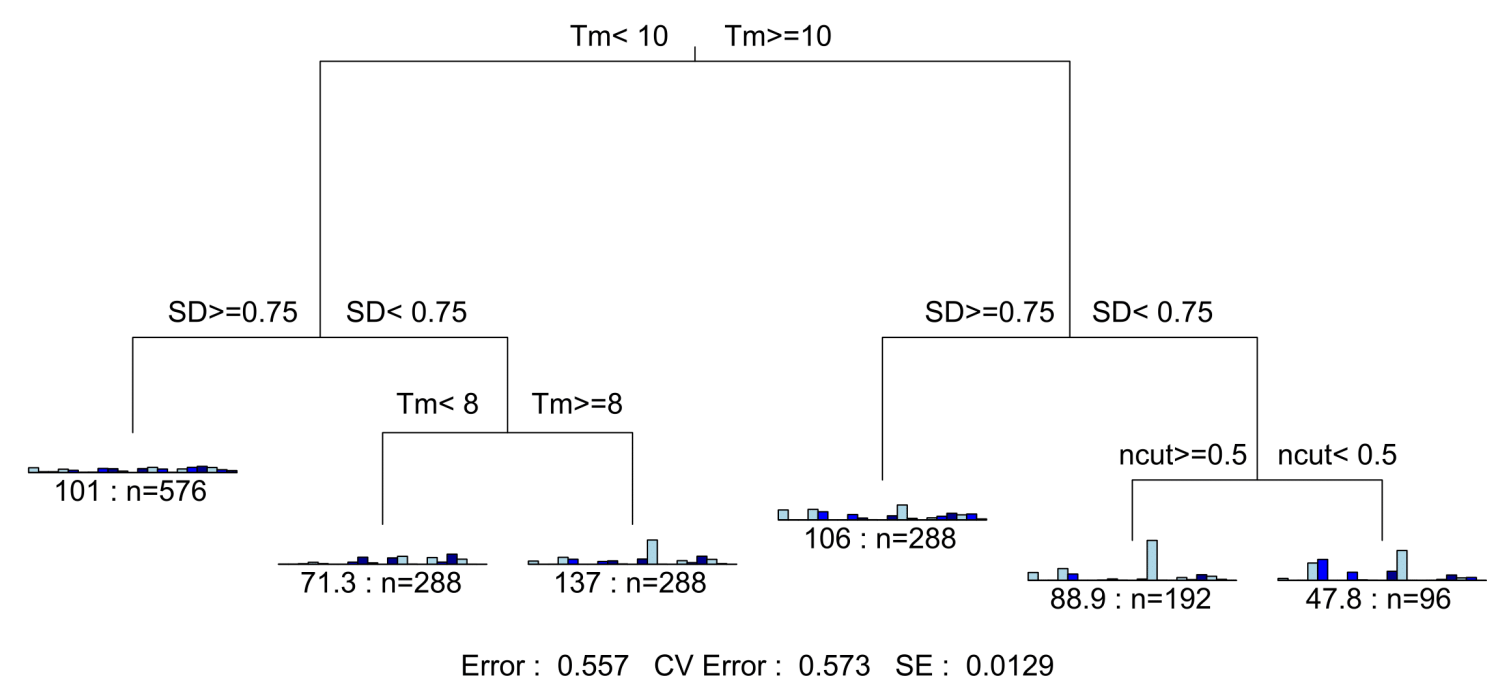

Fig. 5 Multivariate regression trees of a response matrix $\mathbf{Y}$ containing final green biomass of 2 (A) or 21 (B) species explained by control parameters out of matrix $\mathbf{X}$. Barplots show biomass means for all species, with deviance and number of cases at each terminal node.

\subsubsection{Multivariate regression trees}

The hierarchy of the most influential parameters that explained differences in final species composition differed completely between DYNAGRAM2 and DYNAGRAM21 (Fig. 5). Variations in quantitative composition of the two-species modelled grassland (Fig. 5A) were mainly driven by fertility parameters (fertilizer input $\Phi$ and mineralization rate $\theta$ converting organic $\mathrm{N}$ to mineral $\mathrm{N}$ ) and by water supply $P m$. By contrast, defoliation parameters (especially stock density $S D$ ) and temperature $T m$ played the major role in explaining the final composition of the species-rich grassland with 21 species (Fig. 5B). These results show that processes driving the assemblage may be strongly related to species richness.

\subsubsection{Univariate regression trees}

Like species composition, species evenness and survival rate depended mainly on soil fertility ( $\Phi$ and $\theta$ ) for DYNAGRAM2, but on defoliation $(S D)$ for DYNAGRAM21 (Table 3).

By contrast, the hierarchy of parameters influencing final total green biomass was independent of the size of the species pool: the first discriminant parameter was in each case fertilisation intensity $\Phi$, followed by mineralization rate $\theta$ and mean precipitation $P m$. The defoliation regime played no important role in explaining the final standing biomass of a simulated grassland made of 2 or 21 species.

Table 3 Hierarchy of key control parameters resulting from a sensitivity analysis of DYNAGRAM based on MRT and URT on the final biomass of 2 and 21 species. Response variables were individual species biomasses $B_{i}$, total biomass $\left(B_{t o t}\right)$, Simpson evenness $\left(B_{\text {eve }}\right)$, and survival rate ratio $(S)$ at the end of 10-year 1728 simulations for each species pool. Numbers in brackets are thresholds applied to split the tree at the first (first line, in bold) or the second level (second line). Climate parameters: $\mathrm{Tm}$ (temperature), $P m$ (precipitation); soil fertility parameters: $\Phi$ (fertiliser input), $\theta$ (mineralization rate); defoliation parameters: $S D$ (livestock density), ncut (mowing frequency). 


\begin{tabular}{lcc}
\hline Response variables & 2 species & 21 species \\
\hline MRT on $B_{i}$ & $\boldsymbol{\Phi}\{\mathbf{3 5}\}$ & $\boldsymbol{T m}\{\mathbf{1 0}\}$ \\
& $\theta\left\{5.510^{-4}\right\} \quad P m\{65\}$ & $S D\{0.75\} \quad S D\{0.75\}$ \\
\hline URT on $B_{\text {tot }} \quad \boldsymbol{\Phi}\{\mathbf{3 5}\}$ & $\boldsymbol{\Phi}\{\mathbf{3 5}\}$ \\
& $\theta\left\{5.510^{-4}\right\} \quad P m\{65\}$ & $\theta\left\{5.510^{-4}\right\} \quad P m\{65\}$ \\
\hline URT on $B_{\text {eve }}$ & $\boldsymbol{\Phi}\{\mathbf{7 5}\}$ & $\boldsymbol{S D}\{\mathbf{0 . 7 5}\}$ \\
& $\theta\left\{5.510^{-4}\right\} \quad \theta\left\{5.510^{-4}\right\}$ & $S D\{0.25\} \quad T m\{10\}$ \\
\hline URT on $S$ & $\theta\left\{\mathbf{5 . 5} \mathbf{1 0}^{-4}\right\}$ & $\boldsymbol{S D}\{\mathbf{0 . 7 5}\}$ \\
& $\Phi\{35\}$ & $\Phi\{35\} \quad T m\{10\}$ \\
\hline
\end{tabular}

499

\subsubsection{Dynamic trees of species evenness}

501

502

503

504

505

506

507

508

509

510

511

512

513

514

515

516

517

518

519

As the first results of the sensitivity analysis based on composition (MRT) and on Simpson evenness (URT) were very similar, we will focus on this last relevant index of community structure $B_{\text {eve }}$ to investigate in more detail the main effects of the six parameters using dynamic trees (Fig. 6). Results for total biomass and survival rate are provided as Supplementary Material (Online Appendix C, Fig. C.1 and C.2).

Dynamic trees confirmed the strong positive effect of livestock density $S D$ on species evenness with 21 species (Fig. 6B), as compared to other parameters. With two species (Fig. $6 \mathrm{~A}$ ), the main positive effects were also due to the amount of fertilizer $\Phi$ and the maximal mineralization rate $\theta$, which were much less influential with a large species pool. The number of mowing events $n c u t$ showed opposite effects on evenness: slightly positive for two species and negative for 21 species. In both cases, mean temperature $T m$ had a negative effect on evenness.

Despite common trends easily explained by their common structure, the sensitivity analysis revealed strong divergences between the two alternative versions of DYNAGRAM, depending on the size of the species pool, suggesting a shift in key parameters influencing community organization.

A
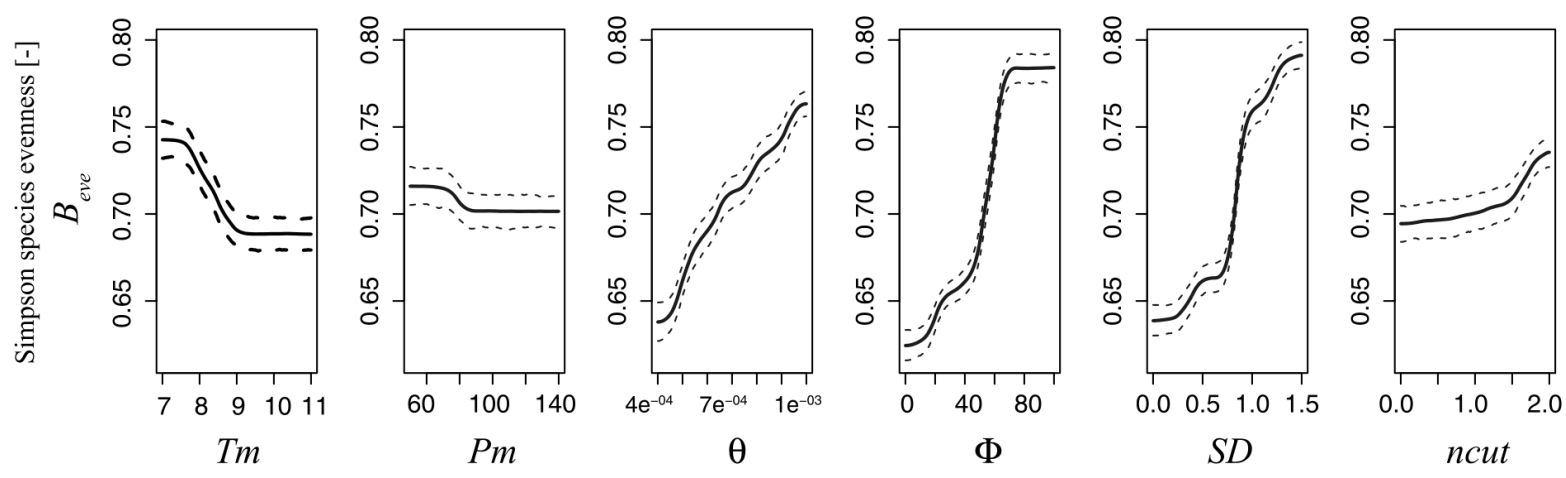

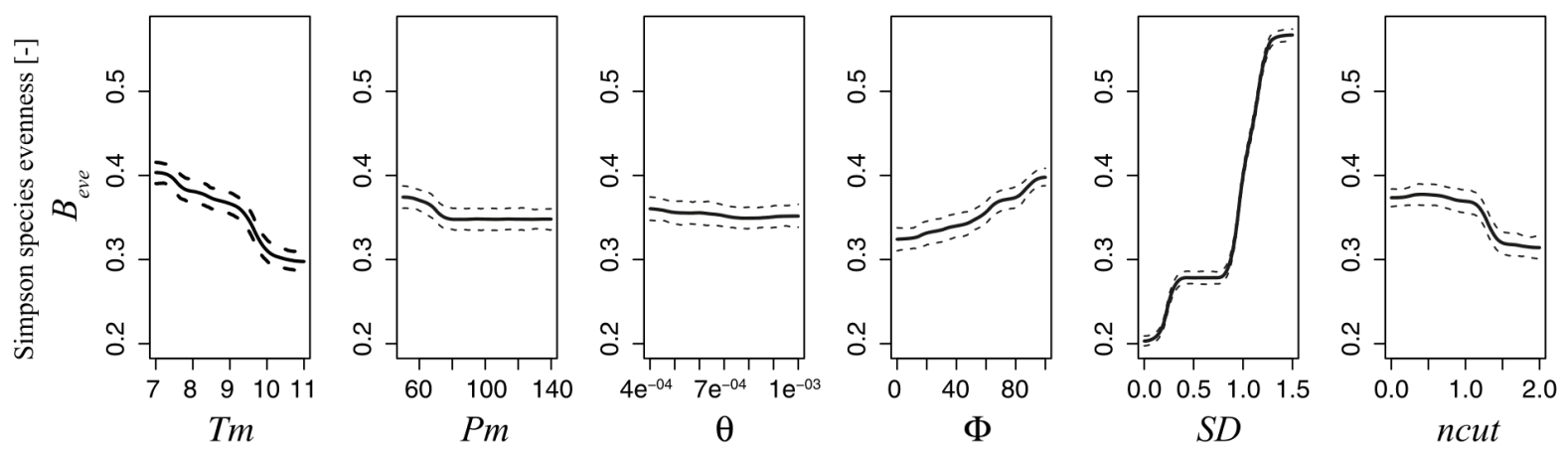

Fig. 6 Main effects of six key parameters on Simpson species evenness $B_{\text {eve }}$, from dynamic trees performed on DYNAGRAM2 (A) and DYNAGRAM21 (B) outputs. Climate parameters: $T m$ (temperature), $P m$ (precipitation); soil fertility parameters: $\Phi$ (fertiliser input), $\theta$ (mineralization rate); defoliation parameters: $S D$ (livestock density), ncut (mowing frequency).

\subsection{Impact of species number on the hierarchy of influential parameters}

Tree-based sensitivity analysis of DYNAGRAM2 and DYNAGRAM21 suggested a shift in key parameters determining the grassland composition according to the size of the species pool. To assess the impact of species number, irrespective to species identity, on the hierarchy of the key parameters, we have to include in the comparison the results of regression trees for DYNAGRAM4 and DYNAGRAM7, each with ten random samples among the full set of 21 species. Results of this comparison are summarized by bar plots (Fig. 7).

A

Species composition

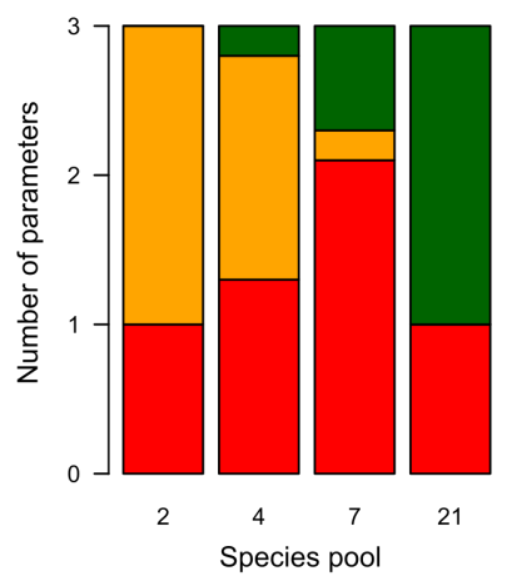

B

Simpson evenness
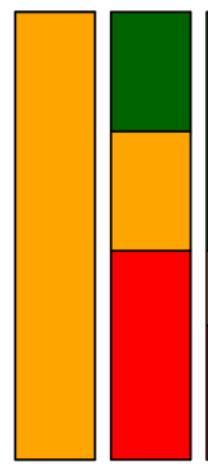

2
C

Total biomass
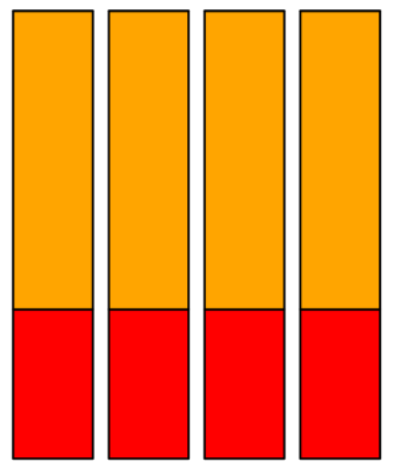

defoliation fertility climate

Fig. 7 Bar plots of the three most influential control parameter categories on species composition (A), Simpson evenness $(\mathbf{B})$ and total green biomass $(\mathbf{C})$ at the end of simulations with 2, 4, 7 and 21 species. Three key parameters were extracted from the first and second splits of each MRT (A) or URT $(\mathbf{B}, \mathbf{C})$. Results for 4 and 7 species are mean numbers from ten random species samples.

A progressive shift from high importance of soil fertility to high importance of defoliation as the number of species increased was evidenced for both species composition (Fig. 7A) and Simpson evenness $B_{\text {eve }}$ (Fig. 7B). A small increase in species number from 2 to 4 induced a small decrease of fertility importance in favour of defoliation and climate. Increasing further species number from 4 to 7 enhanced this trend. Finally, by including all 21 species the 
influence of soil fertility parameters vanished in favour of defoliation parameters. The shift we evidenced in relative parameter influence followed a gradient only driven by the size of the species pool, whatever the species identity.

549 By contrast, results for total biomass $B_{\text {tot }}$ (Fig. 7C) confirmed the absence of any trend, already observed in Table 3: parameters influencing final total green biomass were totally independent of the size of the species pool. $B_{t o t}$ always mainly depended on parameters linked to resource supply: input of $N m$ by soil fertilization $\Phi$, maximal mineralization rate $\theta$ of $N o$ to $\mathrm{Nm}$, and water supply by rainfall $\mathrm{Pm}$.

\section{Discussion}

\subsection{Final model outputs depend on initial species richness}

The positive relationship between the size of the species pool and the final green biomass after 10 growing seasons (Fig. 3A) suggests a better overall productivity of species-rich modelled ecosystems in favourable conditions, whatever species identity. This result is in accordance with our first hypothesis and with the findings of field experiments with artificial plant communities (Hector et al., 1999; Reich et al., 2012). An analysis of these biodiversity experiments (Gross et al., 2013) suggested that interspecific competition generates compensatory dynamics in grasslands that help stabilize community biomass. This stabilizing effect of species richness on community biomass arises because increasing species richness increases mean biomass by a larger amount than it increases variance, thus increasing stability. The contrast with observations in (semi-)natural grasslands, which generally conclude to a negative correlation between species richness and productivity, can be explained by the same reasons that those given in the case of these biodiversity experiments: our simulation experiment considers artificial assemblages of a relatively small number of species (21 species is a relatively low species richness as compared to the one of semi-natural grasslands), which are not likely to coexist in extent plant communities resulting from abiotic and biotic species filtering (Lortie et al., 2004). This contrast between results of simulations or experiments and observations highlights the need to consider multi-species sward in grassland models, which was identified as one of the fifteen key challenges by a panel of European grassland modellers and experts (Kipling et al., 2016b), and a priority for further research. The simulated effect of species diversity on forage production confirms that modelling multispecies swards, along with grassland quality and the impact of management changes, requires further development (Kipling et al., 2016a; van Oijen et al., 2018).

The negative relationship between initial species richness and final species evenness (Fig. 3B) confirms our second hypothesis and the ability of our model to capture competition processes that could lead to dominance of some species. DYNAGRAM also simulates species extinction, and this diversity loss is an expression of competitive exclusion, with dominant species that outcompete some others, depending on environmental conditions.

Furthermore, we observed a decrease in the proportion of surviving species as the size of the species pool increases (Fig. 3C), confirming our third hypothesis. This trend is also in accordance with theory and experiments that suggest that increasing species richness should destabilize the dynamics of individual populations (Gross et al., 2013; Tilman, 1999). This decrease in the species survival ratio means that for high diversity levels not all species initially present can survive. However, contrary to Tilman's tradeoff-based niche theory rooted on a simple resource-reduction competition model (Tilman, 1980), which states that two different species cannot coexist on a single limiting resource, DYNAGRAM is able to simulate the persistence of more species than essential resources. In this model we considered three essential resources (mineral nitrogen, water and light) but we observed long-term 
persistence of more than three species. Species coexistence could partly be explained by the cyclicity of plant growth rate due to seasonal periodic fluctuations of climatic conditions implemented in our model, allowing temporal turnover of species with different temperature optimum for growth.

Among the numerous differences with Tilman's model, we also introduced disturbances due to grassland management (defoliation by grazing and cutting), which as such could be detrimental to some intolerant species and lead to species extinction. However, according to our fourth hypothesis, disturbances are supposed to affect more competitive species and thus prevent competitive exclusion, allowing more species to coexist in the plant community. This is confirmed by our results, as the species survival ratio increased with the defoliation intensity (Fig. 4A). We report the results for 21 species, but a similar relationship was obtained for any size of the species pool (not shown). The importance of defoliation events, mowing or grazing, has also been highlighted for dynamic global vegetation models: the ORCHIDEE model better reproduces seasonal variation of LAI after integrating a management module for defoliation activities (Chang et al., 2013). It could be of interest to extend this result to other disturbances affecting grasslands, such as pest outbreaks and diseases, for which a lack of model development has been reported (Snow et al., 2014).

As expected, the positive correlation between $n$ and $S$ tended to increase with the size of the species pool (Fig. 4B), suggesting that disturbances play a more important stabilizing role in species-rich communities, in which non-equilibrium conditions brought by disturbances and fluctuating environment better favour species coexistence by promoting species turnover and preventing competitive exclusion of subordinate species. The relatively low correlation obtained with DYNAGRAM2 may also be explained by the identity of the selected species, Lolium perenne and Trifolium repens, which, as shown in Table A.2, are both tolerant to defoliation and trampling (Kühn et al., 2004).

These results confirm the need of taking into account the species composition of grassland vegetation to accurately estimate the leaf area index (Ben Touhami and Bellocchi, 2015). They also add to the growing evidence that increased species richness and functional diversity contribute to stabilizing biomass production and enhancing the resilience of grassland ecosystems, as shown both theoretically and experimentally (Cottingham et al., 2001; Gross et al., 2013).

\subsection{A shift in key parameters across a diversity gradient}

Our sensitivity analysis revealed the existence of an unexpected shift in the hierarchy of the most influential parameters on final community structure (MRT on $B_{i}$ : Table 3, Fig. 5 and 7), species evenness (URT and dynamic trees on $B_{\text {eve }}$ : Table 3, Fig. 6 and 7) and species survival ratio (URT on $S$ : Table 3) across a gradient of species richness: as the number of state variables describing the plant community increased, the influence of soil fertility parameters related to stress tended to decline in favour of defoliation parameters related to disturbance. By considering various random combinations of species in addition to the clover-ryegrass mixture for DYNAGRAM4 and DYNAGRAM7, we showed that this general trend was independent of species identity, contrary to our fifth hypothesis.

This importance of soil nitrogen availability for a low diverse assemblage (two species) is consistent with several recent studies that specifically raised the need to model soil nutrient dynamics (Ma et al., 2014; Sándor et al., 2016; Snow et al., 2017). A sensitivity analysis of the biogeochemical grassland model CoupModEL (Senapati et al., 2016) showed that more than half of the critical parameters, recognized as most influential on ecosystem processes, were related to nutrient dynamics. This importance of soil nitrogen availability for DYNAGRAM2 could be explained by the contrasting needs of the two species, expressed by 
strong differences in species-specific parameters $\delta_{i}$ (leaf nitrogen concentration) and $k_{i}$ (halfsaturation constant for nitrogen uptake) between the grass and the legume (Table A.2). The inclusion in the model of the symbiotic fixation of atmospheric nitrogen $\mathrm{N}_{2}$ by the legume (Lazzarotto et al., 2009) would probably have still accentuated this contrast, hence the model sensitivity to resource parameters. Conversely, a species-rich grassland, such as the one modelled by DYNAGRAM21, allows functional redundancy among species, making access to light a key factor of plant growth expressed by a strong importance of defoliation parameters. One further development could consist on taking into account the uncertainty in parameter distribution, following a method for sensitivity analysis recently proposed (Paleari and Confalonieri, 2016).

\subsection{Grassland diversity, productivity and stability}

Contrary to drivers of community structure, parameters influencing final total green biomass did not depend on the size of the species pool (Fig. 7C). Thus, the positive effect of species richness on productivity cannot be explained by changes in key drivers. For any combination of species, biomass production was mainly limited by nutrient and water availability, i.e. stress factors, while disturbances always played a minor role.

Here we assume that the green biomass at the end of the tenth growing season is proportional to the aboveground net primary productivity (ANPP) of the final plant community. We base this assumption on the observation of time series from various simulations that showed strong periodic seasonal similarities after six or seven years of repeated climate and management conditions, suggesting that the system has rapidly reached a cyclic equilibrium (results not shown). A stability analysis based on phase or bifurcation diagrams should be carried out to assess the impact of key forcing parameters, e.g. the fertilisation intensity $\Phi$ and the stock density $S D$, on steady states of the system (Louie et al., 2002). As we simulated seasonal dynamics, cyclic steady states are expected but this stability analysis is out the scope of the present paper.

Another possible critical choice is the date at which values of biomass state variables were kept to compare simulation outcomes. We chose the $1^{\text {st }}$ of October at year 10 of each simulation, just before the second cut and after all other management practices occurred eventually in the last year, but other choices could have been possible, such as the day before the first management event, i.e. the $1^{\text {st }}$ of May at year 10. This second choice led to similar results and to the same conclusions (results not shown).

\subsection{Simplicity or complexity?}

Our study highlights consequences of the chosen number of state variables on model's behaviour. In the case of our grassland model, we evidenced a shift in the hierarchy of key parameters involved in the dynamics of community structure depending on the size of the species pool. This should warn the modeller that mathematical grassland models that simplify the plant community by considering a small number of species or PFTs are likely to reveal impacts of soil fertility, whereas more complex models that include a larger species pool will be more sensitive to disturbance processes. Therefore, this result suggests some conditions in the choice of the number of species to define the hierarchy of drivers involved in plant growth, such as performed in the CoSMo sub-model that ranked disturbances as the most important drivers and nitrogen availability as the less important one (Confalonieri, 2014). This shift of the most influential parameters follows a kind of continuum (Fig. 7). However, whereas the most influential parameters are markedly different between models with 2 and 21 species, the difference between 7 and 21 species is relatively low. Therefore, the choice of 7 
species or PFTs could be a good compromise to take into account functional plant diversity with keeping the number of state variables as lower as possible.

This issue relates to a more general problem in ecological modelling: how to keep the model as simple as possible without missing key variables and processes? DYNAGRAM is simpler than many other grassland models but more complex than other ones. As compared to more parsimonious mechanistic models based on ODE systems (Louie et al., 2002; Siehoff et al., 2011; Tilman, 1985), DYNAGRAM includes a consumption-degradation loop for nitrogen, the main limiting soil nutrient, and takes into account the seasonality of plant growth and resource competition (Lazzarotto et al., 2009). This added complexity was necessary to assess the model's sensitivity to soil fertility, climatic conditions and defoliation.

As both knowledge of grassland ecosystems and computer performance progress, the implementation of more and more details and processes is a general trend in grassland modelling. Our choice of a minimal model complexity implies some strong assumptions. As compared to more detailed models, such as MODVEGE, GEMINI or PROGRASS (Jouven et al., 2006; Lazzarotto et al., 2009; Soussana et al., 2012), DYNAGRAM considers only one single biomass compartment for each species without distinguishing aboveground plant structural components (i.e. vegetative or reproductive, green or dead) and ignores the belowground biomass (roots, rhizomes and storage organs) as well as many associated physiological processes. In accordance with most grassland growth models, DYNAGRAM only simulates vegetative growth and does not include seed reproduction or emergence of new species from the soil seed bank or by seed dispersal.

Model degradation techniques can be applied to assess consequences on model performance (simulation time, prediction accuracy) of reducing the number of variables and parameters in a complex model. Applied to grassland models, they often conclude to the necessity of keeping the full complexity to ensure an acceptable goodness of fit with empirical data (Lohier et al., 2016). In this paper, our goal was more strategical than tactical: we developed DYNAGRAM to address a specific theoretical question about the response of a grassland model to climatic, edaphic and management forcings in function of the number and identity of the state variables describing the plant community. The next step will be to calibrate and to validate the model against experimental data so as to use it for the simulation of climatic and management scenarios applied to real systems. Its performance in terms of computation time as compared to more complex models makes it possible to implement DYNAGRAM as a submodel in a spatially explicit, mosaic landscape model, such as WoodPaM (Gillet, 2008; Peringer et al., 2013).

Alternatives to the development of new models may rely on re-usable components or submodels that could be coupled with generic crop simulators to simulate an assemblage of several species and reproduce plant community dynamics (Confalonieri, 2014). Another promising approach consists in comparing the performance of multiple grassland models so as to implement a multi-model ensemble prediction system in grasslands (Palareti et al., 2016; Sándor et al., 2017).

\section{Conclusion}

Our simulations with DYNAGRAM confirmed most of our expectations but provided new insights on the diversity-productivity-stability relationship. After reaching a cyclic equilibrium, the final structure of the grassland plant community, described by green biomass of a given set of species, depends on the size of species pool. In accordance with the insurance hypothesis (Yachi and Loreau, 1999), increasing species richness insures the ecosystem against declines in its productivity caused by climatic fluctuations and periodic anthropogenic disturbances. However, depending on species identity and environmental conditions, the 
stability of the community, measured by the proportion of surviving species after 10-year simulations, and the evenness component of its diversity tend to decrease with the size of the species pool, due to environmental filtering and competitive exclusion.

Moreover, results of our tree-based sensitivity analysis revealed an unexpected shift in the key drivers of the final community structure, but not of its total biomass, when increasing the size of the species pool from two to 21 species. These findings create new challenges in ecological modelling to be raised through mathematical and simulation studies.

\section{Acknowledgements}

This research takes place in the Long Term Ecological Research (LTER) site Jurassian Arc (http://zaaj.univ-fcomte.fr/?lang=en), which supports long-term interdisciplinary research on the dynamics of mountain socio-ecological systems in the Jura Mountains. TM benefited from a PhD fellowship funded by the University of Franche-Comté. We thank Pascal Carrère, Julien Pottier, Béatrice Laroche and Alexander Peringer for our fruitful discussions and their valuable advice. We acknowledge the two anonymous reviewers for their constructive comments that helped us improve our manuscript.

\section{References}

Al Haj Khaled, R., Duru, M., Theau, J.P., Plantureux, S., Cruz, P., 2005. Variation in leaf traits through seasons and $\mathrm{N}$-availability levels and its consequences for ranking grassland species. J. Veg. Sci. 16, 391. doi:10.1658/11009233(2005)016[0391:VILTTS]2.0.CO;2

Ansquer, P., Theau, J., Cruz, P., 2004. Caractérisation de la diversité fonctionnelle des prairies à flore complexe: vers la construction d'outils de gestion. Fourrages 179, 353368.

Ben Touhami, H., Bellocchi, G., 2015. Bayesian calibration of the Pasture Simulation model (PaSim) to simulate European grasslands under water stress. Ecol. Inform. 30, 356-364. doi:10.1016/j.ecoinf.2015.09.009

Calanca, P., Deléglise, C., Martin, R., Carrère, P., Mosimann, E., 2016. Testing the ability of a simple grassland model to simulate the seasonal effects of drought on herbage growth. F. Crop. Res. 187, 12-23. doi:10.1016/j.fcr.2015.12.008

Calanca, P., Vuichard, N., Campbell, C., Viovy, N., Cozic, A., Fuhrer, J., Soussana, J.F., 2007. Simulating the fluxes of CO2 and N2O in European grasslands with the Pasture Simulation Model (PaSim). Agric. Ecosyst. Environ. 121, 164-174. doi:10.1016/j.agee.2006.12.010

Chang, J.F., Viovy, N., Vuichard, N., Ciais, P., Wang, T., Cozic, A., Lardy, R., Graux, A.I., Klumpp, K., Martin, R., Soussana, J.F., 2013. Incorporating grassland management in ORCHIDEE: Model description and evaluation at 11 eddy-covariance sites in Europe. Geosci. Model Dev. 6, 2165-2181. doi:10.5194/gmd-6-2165-2013

Coffin, D.P., Lauenroth, W.K., 1990. A gap dynamics simulation model of succession in a semiarid grassland. Ecol. Modell. 49, 229-266. doi:10.1016/0304-3800(90)90029-G

Confalonieri, R., 2014. CoSMo: A simple approach for reproducing plant community dynamics using a single instance of generic crop simulators. Ecol. Modell. 286, 1-10. doi:10.1016/j.ecolmodel.2014.04.019 
Cottingham, K.L., Brown, B.L., Lennon, J.T., 2001. Biodiversity may regulate the variability of ecological systems. Ecol. Lett. 4, 72-85.

Cruz, P., Duru, M., Therond, O., Theau, J.P., Ducourtieux, C., 2002. Une nouvelle approche pour caractériser les prairies naturelles et leur valeur d'usage. Fourrages 172, 335-354.

Cruz, P., Theau, J.P., Lecloux, E., Jouany, C., Duru, M., 2010. Typologie fonctionnelle de graminées fourragères pérennes : une classification multitraits. Fourrages 201, 11-17.

De'ath, G., 2002. Multivariate regression trees: a new technique for modelling speciesenvironment relationships. Ecology 83, 1105-1117. doi:10.2307/3071917

De'ath, G., Fabricius, K.E., 2000. Classification and regression trees: A powerful yet simple technique for ecological data analysis. Ecology 81, 3178-3192.

de Mazancourt, C., Isbell, F., Larocque, A., Berendse, F., De Luca, E., Grace, J.B., Haegeman, B., Wayne Polley, H., Roscher, C., Schmid, B., Tilman, D., van Ruijven, J., Weigelt, A., Wilsey, B.J., Loreau, M., 2013. Predicting ecosystem stability from community composition and biodiversity. Ecol. Lett. 16, 617-625. doi:10.1111/ele.12088

Dengler, J., Janišová, M., Török, P., Wellstein, C., 2014. Biodiversity of Palaearctic grasslands : a synthesis. Agric. Ecosyst. Environ. 182, 1-14. doi:10.1016/j.agee.2013.12.015

Duru, M., Adam, M., Cruz, P., Martin, G., Ansquer, P., Ducourtieux, C., Jouany, C., Theau, J.P., Viegas, J., 2009. Modelling above-ground herbage mass for a wide range of grassland community types. Ecol. Modell. 220, 209-225. doi:10.1016/j.ecolmodel.2008.09.015

Eynaud, Y., Nerini, D., Baklouti, M., Poggiale, J.-C., 2012. Towards a simplification of models using regression trees. J. R. Soc. Interface 10, $20120613-20120613$. doi:10.1098/rsif.2012.0613

Gaujour, E., Amiaud, B., Mignolet, C., Plantureux, S., 2012. Factors and processes affecting plant biodiversity in permanent grasslands. A review. Agron. Sustain. Dev. 32, 133-160. doi:10.1007/s13593-011-0015-3

Gillet, F., 2008. Modelling vegetation dynamics in heterogeneous pasture-woodland landscapes. Ecol. Modell. 217, 1-18. doi:10.1016/j.ecolmodel.2008.05.013

Gillet, F., Mauchamp, L., Badot, P.M., Mouly, A., 2016. Recent changes in mountain grasslands: A vegetation resampling study. Ecol. Evol. 6, 2333-2345. doi:10.1002/ece 3.1987

Gramacy, R.B., Taddy, M., Wild, S.M., 2013. Variable selection and sensitivity analysis using dynamic trees, with an application to computer code performance tuning. Ann. Appl. Stat. 7, 51-80. doi:10.1214/12-AOAS590

Graux, A.-I., Klumpp, K., Ma, S., Martin, R., Bellocchi, G., 2016. Plant trait-based assessment of the Pasture Simulation model, in: Sauvage, S., Sánchez-Pérez, J.., Rizzoli, A.. (Eds.), Proceedings of the 8th International Congress on Environmental Modelling and Software, July 10-14, Toulouse, France. Toulouse, France, pp. 518-525.

Graux, A.I., Gaurut, M., Agabriel, J., Baumont, R., Delagarde, R., Delaby, L., Soussana, J.F., 2011. Development of the pasture simulation model for assessing livestock production 
under climate change. Agric. Ecosyst. Environ. 144, 69-91. doi:10.1016/j.agee.2011.07.001

Grime, J.P., 1977. Evidence for the existence of three primary strategies in plants and its relevance to ecological and evolutionary theory. Am. Nat. 111, 1169-1194.

Gross, K., Cardinale, B.J., Fox, J.W., Gonzalez, A., Loreau, M., Polley, H.W., Reich, P.B., van Ruijven, J., Wayne Polley, H., Reich, P.B., van Ruijven, J., 2013. Species richness and the temporal stability of biomass production: A new analysis of recent biodiversity experiments. Am. Nat. 183, 1-12. doi:10.1086/673915

Hector, A., Schmid, C., Beierkuhnlein, C., Caldeira, M.C., Diemer, M., Dimitrakopoulos, P.G., Finn, J. a, Freitas, H., Giller, P.S., Good, J., Harris, R., Hëgberg, P., Huss-danell, K., Joshi, J., Jumpponen, A., Kërner, C., Leadley, P.W., Loreau, M., Minns, A., Mulder, C.P.H., O'donovan, G., Otway, S.J., Pereira, J.S., Prinz, A., Read, D.J., Schererlorenzen, M., Schulze, E.D., Siamantziouras, A.-. S.D., Spehn, E.M., Terry, A.C., Troumbis, A.Y., Woodward, F.I., Yachi, S., Lawton, J.H., 1999. Plant diversity and productivity experiments en European grasslands. Science (80-. ). 286, 1123-1127. doi:10.1126/science.286.5442.1123

Hill, M.O., 1973. Diversity and Evenness: A Unifying Notation and Its Consequences. Ecology 54, 427-432. doi:10.2307/1934352

Homburger, H., Hofer, G., 2012. Diversity change of mountain hay meadows in the Swiss Alps. Basic Appl. Ecol. 13, 132-138. doi:10.1016/j.baae.2011.12.004

Isbell, F., Craven, D., Connolly, J., Loreau, M., Schmid, B., Beierkuhnlein, C., Bezemer, T.M., Bonin, C., Bruelheide, H., de Luca, E., Ebeling, A., Griffin, J.N., Guo, Q., Hautier, Y., Hector, A., Jentsch, A., Kreyling, J., Lanta, V., Manning, P., Meyer, S.T., Mori, A.S., Naeem, S., Niklaus, P.A., Polley, H.W., Reich, P.B., Roscher, C., Seabloom, E.W., Smith, M.D., Thakur, M.P., Tilman, D., Tracy, B.F., van der Putten, W.H., van Ruijven, J., Weigelt, A., Weisser, W.W., Wilsey, B., Eisenhauer, N., 2015. Biodiversity increases the resistance of ecosystem productivity to climate extremes. Nature 526, 574-577. doi:10.1038/nature 15374

Johnson, I.R., 2016. DairyMod and the SGS Pasture Model: A mathematical description of the biophysical model structure.

Jost, L., 2006. Entropy and diversity. Oikos 113, 363-375. doi:10.1111/j.2006.00301299.14714.x

Jouven, M., Carrère, P., Baumont, R., 2006. Model predicting dynamics of biomass, structure and digestibility of herbage in managed permanent pastures. 1. Model description. Grass Forage Sci. 61, 112-124. doi:10.1111/j.1365-2494.2006.00515.x

Julve, P., 2017. Baseflor: index botanique, écologique et chorologique de la flore de France.

Kipling, R.P., Bannink, A., Bellocchi, G., Dalgaard, T., Fox, N.J., Hutchings, N.J., Kjeldsen, C., Lacetera, N., Sinabell, F., Topp, C.F.E., van Oijen, M., Virkajärvi, P., Scollan, N.D., 2016a. Modeling European ruminant production systems: Facing the challenges of climate change. Agric. Syst. 147, 24-37. doi:10.1016/j.agsy.2016.05.007

Kipling, R.P., Virkajärvi, P., Breitsameter, L., Curnel, Y., De Swaef, T., Gustavsson, A.M., Hennart, S., Höglind, M., Järvenranta, K., Minet, J., Nendel, C., Persson, T., PiconCochard, C., Rolinski, S., Sandars, D.L., Scollan, N.D., Sebek, L., Seddaiu, G., Topp, 
C.F.E., Twardy, S., Van Middelkoop, J., Wu, L., Bellocchi, G., 2016b. Key challenges and priorities for modelling European grasslands under climate change. Sci. Total Environ. 566-567, 851-864. doi:10.1016/j.scitotenv.2016.05.144

Kühn, I., Durka, W., Klotz, S., 2004. BiolFlor - A new plant-trait database as a tool for plant invasion ecology. Divers. Distrib. 10, 363-365. doi:10.1111/j.1366-9516.2004.00106.x

Lauenroth, W.K., Urban, D.L., Coffin, D.P., Parton, W.J., Shugart, H.H., Kirchner, T.B., Smith, T.M., 1993. Modeling vegetation structure-ecosystem process interactions across sites and ecosystems. Ecol. Modell. 67, 49-80. doi:10.1016/0304-3800(93)90099-E

Lazzarotto, P., Calanca, P., Fuhrer, J., 2009. Dynamics of grass-clover mixtures-An analysis of the response to management with the PROductive GRASsland Simulator (PROGRASS). Ecol. Modell. 220, 703-724. doi:10.1016/j.ecolmodel.2008.11.023

Lohier, T., Jabot, F., Weigelt, A., Schmid, B., Deffuant, G., 2016. Predicting stochastic community dynamics in grasslands under the assumption of competitive symmetry. $\mathrm{J}$. Theor. Biol. 399, 53-61. doi:10.1016/j.jtbi.2016.03.043

Lohmann, D., Guo, T., Tietjen, B., 2017. Zooming in on coarse plant functional typessimulated response of savanna vegetation composition in response to aridity and grazing. Theor. Ecol. 1-13. doi:10.1007/s 12080-017-0356-x

Lortie, C.J., Brooker, R.W., Choler, P., Kikvidze, Z., Pugnaire, F.I., Callaway, R.M., Pugnaire, I., Lortie, J., 2004. Rethinking plant community theory. Oikos 107, 433-438. doi:10.1111/j.0030-1299.2004.13250.x

Louie, K., Wake, G.C., Lambert, G., MacKay, A., Barker, D., 2002. A delay model for the growth of ryegrass-clover mixtures: formulation and preliminary simulations. Ecol. Modell. 155, 31-42. doi:10.1016/S0304-3800(02)00063-7

Ma, S., Lardy, R., Graux, A.I., Ben Touhami, H., Klumpp, K., Martin, R., Bellocchi, G., 2014. Regional-scale analysis of carbon and water cycles on managed grassland systems. Environ. Model. Softw. 72, 356-371. doi:10.1016/j.envsoft.2015.03.007

Makler-Pick, V., Gal, G., Gorfine, M., Hipsey, M.R., Carmel, Y., 2011. Sensitivity analysis for complex ecological models - A new approach. Environ. Model. Softw. 26, 124-134. doi:10.1016/j.envsoft.2010.06.010

Mauchamp, L., Gillet, F., Mouly, A., Badot, P.-M., 2012. Les prairies : biodiversité et services écosystémiques. Presses universitaires de Franche-Comté, Besançon.

Mauchamp, L., Mouly, A., Badot, P.-M., Gillet, F., 2014. Impact of management type and intensity on multiple facets of grassland biodiversity in the French Jura Mountains. Appl. Veg. Sci. 17, 645-657. doi:10.1111/avsc.12116

Mauchamp, L., Mouly, A., Badot, P.M., Gillet, F., 2016. Impact of nitrogen inputs on multiple facets of plant biodiversity in mountain grasslands: Does nutrient source matter? Appl. Veg. Sci. 19, 206-217. doi:10.1111/avsc.12214

McCall, D.G., Bishop-Hurley, G.J., 2003. A pasture growth model for use in a whole-farm dairy production model. Agric. Syst. 76, 1183-1205. doi:10.1016/S0308521X(02)00104-X

Mitchell, R.J., Hewison, R.L., Britton, A.J., Brooker, R.W., Cummins, R.P., Fielding, D.A., Fisher, J.M., Gilbert, D.J., Hester, A.J., Hurskainen, S., Pakeman, R.J., Potts, J.M., 
Riach, D., 2017. Forty years of change in Scottish grassland vegetation: Increased richness, decreased diversity and increased dominance. Biol. Conserv. 212, 327-336. doi:10.1016/j.biocon.2017.06.027

Palareti, G., Legnani, C., Cosmi, B., Antonucci, E., Erba, N., Poli, D., Testa, S., Tosetto, A., 2016. Comparison between different D-Dimer cutoff values to assess the individual risk of recurrent venous thromboembolism: analysis of results obtained in the DULCIS study. Int. J. Lab. Hematol. 38, 42-49. doi:10.1111/ijlh.12426

Paleari, L., Confalonieri, R., 2016. Sensitivity analysis of a sensitivity analysis: We are likely overlooking the impact of distributional assumptions. Ecol. Modell. 340, 57-63. doi:10.1016/j.ecolmodel.2016.09.008

Peringer, A., Siehoff, S., Chételat, J., Spiegelberger, T., Buttler, A., Gillet, F., 2013. Past and future landscape dynamics in pasture-woodlands of the Swiss Jura Mountains under climate change. Ecol. Soc. 18, art11. doi:10.5751/ES-05600-180311

Perronne, R., Mauchamp, L., Badot, P.-M., Gillet, F., 2014. Contrasted taxonomic, phylogenetic and functional diversity patterns in semi-natural permanent grasslands along an altitudinal gradient. Plant Ecol. Evol. 147, 165-175. doi:10.5091/plecevo.2014.885

Peters, D.P.C., 2002. Plant species dominance at a grassland-shrubland ecotone: An individual-based gap dynamics model of herbaceous and woody species. Ecol. Modell. 152, 5-32. doi:10.1016/S0304-3800(01)00460-4

Pierce, S., Negreiros, D., Cerabolini, B.E.L., Kattge, J., Díaz, S., Kleyer, M., Shipley, B., Wright, S.J., Soudzilovskaia, N.A., Onipchenko, V.G., van Bodegom, P.M., FrenetteDussault, C., Weiher, E., Pinho, B.X., Cornelissen, J.H.C., Grime, J.P., Thompson, K., Hunt, R., Wilson, P.J., Buffa, G., Nyakunga, O.C., Reich, P.B., Caccianiga, M., Mangili, F., Ceriani, R.M., Luzzaro, A., Brusa, G., Siefert, A., Barbosa, N.P.U., Chapin, F.S., Cornwell, W.K., Fang, J., Fernandes, G.W., Garnier, E., Le Stradic, S., Peñuelas, J., Melo, F.P.L., Slaviero, A., Tabarelli, M., Tampucci, D., 2017. A global method for calculating plant CSR ecological strategies applied across biomes world-wide. Funct. Ecol. 31, 444-457. doi:10.1111/1365-2435.12722

R Core Team, 2017. R: A language and environment for statistical computing.

Ravalico, J.K., Maier, H.R., Dandy, G.C., Norton, J.P., Croke, B.F.W., others, 2005. A Comparison of Sensitivity Analysis Techniques for Complex Models for Environmental Management. Int. Congr. Model. Simul. 2005 Melb. Vic 2533-2539.

Reich, P.B., Tilman, D., Isbell, F., Mueller, K., Hobbie, S.E., Flynn, D.F.B., Eisenhauer, N., 2012. Impacts of biodiversity loss escalate through time as redundancy fades. Science (80-. ). 336, 589-592. doi:10.1126/science.1217909

Riedo, M., Grub, A., Rosset, M., Fuhrer, J., 1998. A pasture simulation model for dry matter production, and fluxes of carbon, nitrogen, water and energy. Ecol. Modell. 105, 141183. doi:10.1016/S0304-3800(97)00110-5

Ryser, P., Urbas, P., 2000. Ecological significance of leaf life span among Central European grass species. Oikos 91, 41-50. doi:10.1034/j.1600-0706.2000.910104.x

Sándor, R., Barcza, Z., Acutis, M., Doro, L., Hidy, D., Köchy, M., Minet, J., Lellei-Kovács, E., Ma, S., Perego, A., Rolinski, S., Ruget, F., Sanna, M., Seddaiu, G., Wu, L., 
Bellocchi, G., 2017. Multi-model simulation of soil temperature, soil water content and biomass in Euro-Mediterranean grasslands: Uncertainties and ensemble performance. Eur. J. Agron. 88, 22-40. doi:10.1016/j.eja.2016.06.006

Sándor, R., Barcza, Z., Hidy, D., Lellei-Kovács, E., Ma, S., Bellocchi, G., 2016. Modelling of grassland fluxes in Europe: Evaluation of two biogeochemical models. Agric. Ecosyst. Environ. 215, 1-19. doi:10.1016/j.agee.2015.09.001

Schapendonk, A.H.C.M., Stol, W., Van Kraalingen, D.W.G., Bouman, B.A.M., 1998. LINGRA, a sink/source model to simulate grassland productivity in Europe. Eur. J. Agron. 9, 87-100. doi:10.1016/S1161-0301(98)00027-6

Senapati, N., Jansson, P.E., Smith, P., Chabbi, A., 2016. Modelling heat, water and carbon fluxes in mown grassland under multi-objective and multi-criteria constraints. Environ. Model. Softw. 80, 201-224. doi:10.1016/j.envsoft.2016.02.025

Siehoff, S., Lennartz, G., Heilburg, I.C., Roß-Nickoll, M., Ratte, H.T., Preuss, T.G., 2011. Process-based modeling of grassland dynamics built on ecological indicator values for land use. Ecol. Modell. 222, 3854-3868. doi:10.1016/j.ecolmodel.2011.10.003

Snow, V.O., Cichota, R., McAuliffe, R.J., Hutchings, N.J., Vejlin, J., 2017. Increasing the spatial scale of process-based agricultural systems models by representing heterogeneity: The case of urine patches in grazed pastures. Environ. Model. Softw. 90, 89-106. doi:10.1016/j.envsoft.2017.01.005

Snow, V.O., Rotz, C.A., Moore, A.D., Martin-Clouaire, R., Johnson, I.R., Hutchings, N.J., Eckard, R.J., 2014. The challenges - and some solutions - to process-based modelling of grazed agricultural systems. Environ. Model. Softw. 62, 420-436. doi:10.1016/j.envsoft.2014.03.009

Soetaert, K., Petzoldt, T., Setzer, R.W., 2010. Package deSolve : Solving Initial Value Differential Equations in R. J. Stat. Softw. 33, 1-25. doi:10.18637/jss.v033.i09

Soussana, J.F., Maire, V., Gross, N., Bachelet, B., Pagès, L., Martin, R., Hill, D., Wirth, C., 2012. Gemini: A grassland model simulating the role of plant traits for community dynamics and ecosystem functioning. Parameterization and evaluation. Ecol. Modell. 231, 134-145. doi:10.1016/j.ecolmodel.2012.02.002

Taddy, M.A., Gramacy, R.B., Polson, N.G., 2011. Dynamic Trees for Learning and Design. J. Am. Stat. Assoc. 106, 109-123. doi:10.1198/jasa.2011.ap09769

Taubert, F., Frank, K., Huth, A., 2012. A review of grassland models in the biofuel context. Ecol. Modell. 245, 84-93. doi:10.1016/j.ecolmodel.2012.04.007

Thornley, J.H.M., 1998. Grassland dynamics: an ecosystem simulation model. CAB International.

Tilman, D., 1999. The ecological consequences of changes in biodiversity: A search for general principles. Ecology 80, 1455-1474.

Tilman, D., 1985. The resource-ratio hypothesis of plant succession. Am. Nat. 125, 827-852. doi:10.1086/284382

Tilman, D., 1980. Resources: A graphical-mechanistic approach to competition and predation. Am. Nat. 116, 362-393. doi:10.1086/283633

van Oijen, M., Bellocchi, G., Höglind, M., 2018. Effects of Climate Change on Grassland 
Biodiversity and Productivity: The Need for a Diversity of Models. Agronomy 8, 14. doi:10.3390/agronomy8020014

Vaze, J., Johnston, W.H., Teng, J., Tuteja, N.K., Johnson, I., 2009. Development and implementation of a generic pasture growth model (CLASS PGM). Environ. Model. Softw. 24, 107-114. doi:10.1016/j.envsoft.2008.06.003

Weiss, L., Pfestorf, H., May, F., Körner, K., Boch, S., Fischer, M., Müller, J., Prati, D., Socher, S.A., Jeltsch, F., 2014. Grazing response patterns indicate isolation of seminatural European grasslands. Oikos 123, 599-612. doi:10.1111/j.16000706.2013.00957.x

Wesche, K., Krause, B., Culmsee, H., Leuschner, C., 2012. Fifty years of change in Central European grassland vegetation: Large losses in species richness and animal-pollinated plants. Biol. Conserv. 150, 76-85. doi:10.1016/j.biocon.2012.02.015

Wiegand, T., Wiegand, K., Pütz, S., 2008. Grassland Models. Encycl. Ecol. doi:10.1016/b978-008045405-4.00185-3

Wilson, J.B., Peet, R.K., Dengler, J., Pärtel, M., 2012. Plant species richness: The world records. J. Veg. Sci. 23, 796-802. doi:10.1111/j.1654-1103.2012.01400.x

Yachi, S., Loreau, M., 1999. Biodiversity and ecosystem productivity in a fluctuating environment: the insurance hypothesis. Proc. Natl. Acad. Sci. U. S. A. 96, 1463-1468. doi:10.1073/pnas.96.4.1463 


\section{Appendix A: Variables and parameters of DYNAGRAM}

1010

1011 Table A.1 Summary of all variables and parameters of DYNAGRAM. Values of the species1012 specific parameters are given in Table A.2.

1013

\begin{tabular}{|c|c|c|c|}
\hline Symbol & Definition & Unit & Value \\
\hline \multicolumn{4}{|c|}{ State variables } \\
\hline$B_{i}$ & Green biomass of species or PFT $i$ & kg DM ha-1 & $B_{i}(0)=200 / \mathrm{n}$ \\
\hline No & Organic nitrogen, stored in the soil organic matter & $\mathrm{kg} \mathrm{N} \mathrm{ha}^{-1}$ & $N o(0)=5800$ \\
\hline$N m$ & $\begin{array}{l}\text { Mineral nitrogen (nitrate and ammonium) in the soil solution, available } \\
\text { for plant uptake }\end{array}$ & $\mathrm{kg} \mathrm{N} \mathrm{ha}^{-1}$ & $N m(0)=20$ \\
\hline$W R$ & Water reserve in the soil, available for plant uptake & $\mathrm{mm}$ & $W R(0)=\mathrm{WHC}$ \\
\hline \multicolumn{4}{|c|}{ Climatic forcing variables } \\
\hline$T$ & Surface temperature & ${ }^{\circ} \mathrm{C}$ & function \\
\hline$P$ & Daily precipitation & $\mathrm{mm} \mathrm{d}^{-1}$ & function \\
\hline$P A R$ & Photosynthetically active radiation & $M J m^{-2} d^{-1}$ & function \\
\hline PET & Potential evapotranspiration & $\mathrm{mm} \mathrm{d}^{-1}$ & function \\
\hline \multicolumn{4}{|c|}{ Plant species-specific parameters } \\
\hline$n$ & Number of species or PFTs & [count] & $\{2,4,7,21\}$ \\
\hline$S L A_{i}$ & Specific leaf area & $\mathrm{m}^{2} \mathrm{~g}^{-1}$ & species-specific \\
\hline$\lambda_{i}$ & Proportion of biomass removed by a mowing event & $d^{-1}$ & species-specific \\
\hline$\rho_{i}$ & Appetence for feeding regime of cattle & {$[-]$} & species-specific \\
\hline$\sigma_{i}$ & Utilization indicator value for the trampling tolerance & {$[-]$} & species-specific \\
\hline$\delta_{i}$ & Leaf nitrogen content & $\operatorname{kg~N}(\mathrm{kg} \mathrm{DM})^{-1}$ & species-specific \\
\hline$k_{i}$ & $\begin{array}{l}\text { Half-saturation constant: resource level at which growth rate is half its } \\
\text { maximum }\end{array}$ & $\mathrm{kg} \mathrm{N} \mathrm{ha}^{-1}$ & species-specific \\
\hline$\mu_{i}$ & Basic senescence rate of leaves & $d^{-1}$ & species-specific \\
\hline$T_{1, i}$ & Lower limit of optimum of daily temperature for photosynthesis & ${ }^{\circ} \mathrm{C}$ & species-specific \\
\hline$\eta_{i}$ & Water stress tolerance exponent & {$[-]$} & species-specific \\
\hline \multicolumn{4}{|c|}{ Plant growth processes and tolerance parameters } \\
\hline$T_{0}$ & Base temperature for light utilization and development & ${ }^{\circ} \mathrm{C}$ & 3 \\
\hline$T_{2}$ & Higher limit of optimum of daily temperature for photosynthesis & ${ }^{\circ} \mathrm{C}$ & 20 \\
\hline$T_{3}$ & Maximal temperature for light utilization and development & ${ }^{\circ} \mathrm{C}$ & 40 \\
\hline$R U E_{\max }$ & Maximum radiation use efficiency & g DM MJ-1 & 3 \\
\hline$L A M$ & Proportion of laminae in green biomass & {$[-]$} & 0.68 \\
\hline$\alpha$ & Extinction coefficient & {$[-]$} & 0.6 \\
\hline$v$ & Holling coefficient for mineral nitrogen consumption & {$[-]$} & 2 \\
\hline$n g$ & Holling coefficient for green biomass removal by grazing & {$[-]$} & 2 \\
\hline$T_{\text {tol }}$ & Amplification exponent of the control function $f(X)$ of trampling & {$[-]$} & 0.5 \\
\hline \multicolumn{4}{|c|}{ Soil parameters } \\
\hline$\theta$ & Nitrogen mineralization rate & $d^{-1}$ & $710^{-4}$ \\
\hline$N m_{\max }$ & Maximal amount of $\mathrm{Nm}$ stored in the soil before lixiviation & $\mathrm{kg} \mathrm{N} \mathrm{ha}^{-1}$ & 120 \\
\hline WHC & Volumetric water content at field capacity & $\mathrm{mm}$ & 150 \\
\hline$P W P$ & Volumetric soil water content at permanent wilting point & $\mathrm{mm}$ & 7.5 \\
\hline $\operatorname{Tm}_{1}$ & Critical temperature for maximal mineralization rate of $\mathrm{No}$ to $\mathrm{Nm}$ & ${ }^{\circ} \mathrm{C}$ & 40 \\
\hline $\mathrm{Tm}_{2}$ & Empirical parameters describing effect of temperature on mineralization & ${ }^{\circ} \mathrm{C}$ & 31.79 \\
\hline$g_{T}$ & Empirical parameters describing effect of temperature on mineralization & {$[-]$} & 3.36 \\
\hline
\end{tabular}




\begin{tabular}{|c|c|c|c|}
\hline$g_{W 1}$ & Empirical parameters describing effect of soil water on mineralization & {$[-]$} & 1 \\
\hline$g_{W 2}$ & Empirical parameter describing effect of soil water on mineralization & {$[-]$} & 6.63 \\
\hline$g_{\mathrm{W} 3}$ & Empirical parameter describing effect of soil water on mineralization & {$[-]$} & -5.69 \\
\hline$P E T_{\max }$ & Maximal measured value of PET & $\mathrm{mm} \mathrm{d}^{-1}$ & 3.75 \\
\hline$\beta_{1}$ & Empirical parameter for fitting $f_{W}$ function of Jouven et al. & {$[-]$} & 6.467 \\
\hline$\beta_{2}$ & Empirical parameter for fitting $f_{W}$ function of Jouven et al. & {$[-]$} & $7.62310^{-8}$ \\
\hline \multicolumn{4}{|c|}{ Management parameters and auxiliary variables } \\
\hline$S D$ & Livestock density, number of adult bovine units per hectare & $\mathrm{LU} \mathrm{ha}^{-1}$ & {$\left[0, S D_{\max }\right]$} \\
\hline$S D_{\max }$ & Maximal possible livestock density & LU ha-1 & 3 \\
\hline$\kappa$ & Daily consumption of 1 adult bovine unit & $\mathrm{kg} \mathrm{DM} \mathrm{LU} \mathrm{U}^{-1} \mathrm{~d}^{-1}$ & 18 \\
\hline$\Phi$ & Yearly input of mineral nitrogen fertilizer in the soil & $\mathrm{kg} \mathrm{N} \mathrm{ha}^{-1} \mathrm{a}^{-1}$ & 0 \\
\hline$\Phi_{u}$ & Rate of mineral nitrogen restitution by cattle urine deposition & $\mathrm{kg} \mathrm{N} \mathrm{ha}^{-1} \mathrm{~d}^{-1}$ & 0.315 \\
\hline$\Phi_{d}$ & Rate of organic nitrogen restitution by cattle dung deposition & $\mathrm{kg} \mathrm{N} \mathrm{ha}^{-1} \mathrm{~d}^{-1}$ & 0.236 \\
\hline ncut & Number of mowing events per year & {$[-]$} & $\{0,1,2,3\}$ \\
\hline \multicolumn{4}{|c|}{ Climatic parameters } \\
\hline$\omega$ & Seasonal oscillation period, conversion of radian in days & $\mathrm{d}^{-1}$ & $2 \pi / 365$ \\
\hline $\operatorname{Tm}$ & Mean annual values of temperature $T$ & ${ }^{\circ} \mathrm{C}$ & 8.517 \\
\hline$P m$ & Mean annual values of sum of monthly precipitations $P$ & $\mathrm{~mm} \mathrm{~d}^{-1}$ & 2.056 \\
\hline PARm & Mean annual values of $P A R$ & $M J m^{-2} d^{-1}$ & 5.434 \\
\hline PETm & Mean annual values of $P E T$ & $\mathrm{~mm} \mathrm{~d}^{-1}$ & 1.93 \\
\hline$T a$ & Amplitude of $T$ & ${ }^{\circ} \mathrm{C}$ & 14.81 \\
\hline $\mathrm{Pa}$ & Amplitude of $P$ & $\mathrm{~mm} \mathrm{~d}^{-1}$ & 1.168 \\
\hline PARa & Amplitude of $P A R$ & $M J m^{-2} d^{-1}$ & 7.344 \\
\hline PETa & Amplitude of $P E T$ & $\mathrm{~mm} \mathrm{~d}^{-1}$ & 3.542 \\
\hline$\Psi_{T}$ & Origin phase of oscillations for $T$ & $\mathrm{~d}$ & 106.5 \\
\hline$\Psi_{P}$ & Origin phase of oscillations for $P$ & d & 110.5 \\
\hline$\Psi_{P A R}$ & Origin phase of oscillations for $P A R$ & $\mathrm{~d}$ & 80.8 \\
\hline$\Psi_{P E T}$ & Origin phase of oscillations for $P E T$ & $\mathrm{~d}$ & 87.76 \\
\hline
\end{tabular}


1016 Table A.2 List of the 21 herbaceous species to be selected in the alternative versions of 1017 DYNAGRAM, with their plant functional type (PFT), CSR strategy (Pierce et al., 2017) and 1018 species-specific parameter values: SLA specific leaf area (Perronne et al., 2014); $\lambda$ proportion 1019 of biomass removed by a mowing event, estimated from canopy height (Perronne et al.,

1020 2014); $\rho$ appetence for cattle (Kühn et al., 2004); $\sigma$ trampling tolerance (Kühn et al., 2004); $\delta$

1021 leaf nitrogen content (Soussana et al., 2012); $k$ half-saturation constant of the nitrogen

1022 resource, estimated from $N$ requirement (Julve, 2017); $\mu$ leaf senescence rate (Ryser and

1023 Urbas, 2000); $T_{1}$ lower limit of optimal growth temperature (Al Haj Khaled et al., 2005); $\eta$

1024 water requirement (Julve, 2017). In bold, the two species considered for DYNAGRAM2 and

1025 kept for defining the assemblages of DYNAGRAM4 and DYNAGRAM7. PFTs are defined by

1026 four groups of grasses and three life forms of dicots (Ansquer et al., 2004; Cruz et al., 2002):

1027 A, early and fast-growing grasses in fertile and frequently disturbed grasslands; B,

1028 competitive and productive grasses in fertile and unfrequently disturbed grasslands; C, late

1029 and slow-growing grasses in infertile and frequently disturbed grasslands; D, late and slow-

1030 growing grasses in infertile and unfrequently disturbed grasslands; E, erect forbs; R, rosette

1031 forbs; L, legumes.

1032

\begin{tabular}{|c|c|c|c|c|c|c|c|c|c|c|c|c|}
\hline Symbol & Name & PFT & CSR & $S L A$ & $\lambda$ & $\rho$ & $\sigma$ & $\delta$ & $k$ & $\mu$ & $T_{1}$ & $\eta$ \\
\hline Lol.per & Lolium perenne & A & $\mathrm{R} / \mathrm{CR}$ & 0.0286 & 0.40 & 9 & 8 & 0.0182 & 13.00 & .0303 & 7.5 & 1.000 \\
\hline Ely.rep & Elymus repens & 18 & CSR & 0.0233 & 0.70 & 6 & 7 & 0.0106 & 12.00 & .0178 & 9.5 & 1.000 \\
\hline Ant.odo & Anthoxanthum odo & $\mathrm{B}$ & $\mathrm{S} / \mathrm{SR}$ & 0.0283 & 0.70 & 4 & 5 & 0.0173 & 12.00 & 0.0192 & 11.0 & 1.000 \\
\hline Arr.ela & Arrhenatherum elatius & $\mathrm{B}$ & SR/CSR & 0.0299 & 0.80 & 8 & 3 & 0.0238 & 11.00 & 0.0250 & 8.5 & 1.000 \\
\hline Dac.glo & Dactylis glomerata & B & CSR & 0.0253 & 0.50 & 8 & 6 & 0.0094 & 11.00 & 0.0230 & 10.0 & 1.000 \\
\hline Poa.tri & Poa trivialis & $D$ & CSR & 0.0331 & 0.50 & 7 & 6 & 0.0224 & 11.00 & 0.0250 & 8.0 & 2.000 \\
\hline Agr.cap & Agrostis capillaris & $\mathrm{C}$ & SR & 0.0286 & 0.80 & 5 & 5 & 0.0205 & 7.50 & 0.0205 & 16.0 & 1.000 \\
\hline Bro.ere & Bromopst & 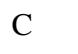 & S/SR & 0.0155 & 0.90 & 12 & 1 & 0.0105 & 5.15 & 0.0160 & 15.3 & 0.500 \\
\hline Fes.rub & Festuca $r$ & $\mathrm{C}$ & SR & 0.0164 & 0.90 & 5 & 6 & 0.0137 & 7.00 & 0.0138 & 13.0 & 1.000 \\
\hline Nar.str & Nardus stricta & $C$ & $\mathrm{~S}$ & 0.0110 & 0.58 & 9 & 2 & 0.0175 & 4.85 & 0.0115 & 15.0 & 1.000 \\
\hline Tri.fla & Trisetum flavesc & $\mathrm{C}$ & SR/CSR & 0.0205 & 0.91 & 5 & 4 & 0.0130 & 6.00 & 0.0212 & 14.0 & 1.000 \\
\hline Bra.pin & Brachypodium pinnatum & $\mathrm{D}$ & SR/CSR & 0.0234 & 0.92 & 12 & 1 & 0.0202 & 6.25 & 0.0167 & 16.5 & 1.000 \\
\hline Poa.cha & Poa chaixii & $\mathrm{D}$ & S/CSR & 0.0207 & 0.40 & 3 & 4 & 0.0175 & 10.00 & 0.0250 & 8.0 & 1.000 \\
\hline Ger.syl & Geranium sylvaticum & $\mathrm{E}$ & CSR & 0.0315 & 0.82 & 8 & 3 & 0.0175 & 10.50 & 0.0220 & 8.5 & 2.000 \\
\hline Her.sph & Heracleum sphondylium & $\mathrm{E}$ & $\mathrm{C}$ & 0.0230 & 0.75 & 6 & 3 & 0.0175 & 11.00 & 0.0176 & 9.0 & 1.000 \\
\hline Pla.lan & Plantago lanceolata & $\mathrm{R}$ & $\mathrm{C} / \mathrm{CR}$ & 0.0196 & 0.69 & 3 & 9 & 0.0191 & 9.00 & 0.0159 & 12.0 & 1.000 \\
\hline Tar.off & Taraxacum officinale & $\mathrm{R}$ & CR & 0.0324 & 0.92 & 7 & 8 & 0.0175 & 9.00 & 0.0224 & 12.5 & 1.000 \\
\hline Ver.cha & Veronica chamaedrys & 10 & SR/CSR & 0.0277 & 0.80 & 3 & 7 & 0.0196 & 9.00 & 0.0220 & 13.0 & 1.000 \\
\hline Lot.cor & Lotus corniculatus & $\mathrm{L}$ & $\mathrm{R} / \mathrm{SR}$ & 0.0224 & 0.95 & 9 & 1 & 0.0175 & 7.75 & 0.0173 & 11.5 & 0.707 \\
\hline Tri.pra & Trifolium pratense & $\mathrm{L}$ & $\mathrm{R} / \mathrm{CSR}$ & 0.0228 & 0.82 & 8 & 3 & 0.0196 & 8.00 & 0.0175 & 11.5 & 1.000 \\
\hline Tri.rep & Trifolium repens & $\mathrm{L}$ & $\mathrm{R} / \mathrm{CR}$ & 0.0343 & 0.90 & 9 & 8 & 0.0195 & 8.50 & 0.0234 & 13.0 & 1.000 \\
\hline
\end{tabular}

1033 


\section{Online Supplementary Material}

1036 The following supplementary material is available for this article.

1038 Appendix B Preliminary identification stage of the sensitivity analysis of DYNAGRAM. This

1039 appendix details all results of the preliminary sensitivity analysis we performed to select the 1040 six key control parameters. Results stay in the three following tables:

1041 Table B.1 Parameter sensitivity of total green biomass $B_{t o t}$ to deviations by $\pm 20 \%$ from the 1042 default parameter values for DYNAGRAM2 and DYNAGRAM21. Changes were applied 1043 independently for each parameter, all other parameters keeping their default values.

1044 Table B.2 Parameter sensitivity of species evenness $B_{\text {eve }}$ to deviations by $\pm 20 \%$ from the 1045 default parameter values for DYNAGRAM2 and DYNAGRAM21. Changes were applied 1046 independently for each parameter, all other parameters keeping their default values.

1047 Table B.3 Ranking of parameters according to the sensitivity of total green biomass $B_{t o t}$ and 1048 of species evenness $B_{\text {eve }}$ to variations in the default parameters for DYNAGRAM2 and

1049 DYNAGRAM21. Values were computed by both increasing and decreasing the default value of 1050 each parameter. Parameters were ranked according to the mean values of the 2 and 21 species.

Appendix C Main effects of key control parameters on biomass and species survival ratio. This appendix contains two figures that detail the main effects of the six parameters on total green biomass $B_{t o t}$ and species survival ratio $S$ as revealed by dynamic trees.

Figure C.1 Main effects of six key parameters on total green biomass $B_{t o t}$, from dynamic trees performed on DYNAGRAM2 (A) and DYNAGRAM21 (B) outputs. Climate parameters: Tm (temperature), $P m$ (precipitation); soil fertility parameters: $\Phi$ (fertiliser input), $\theta$ (mineralization rate); defoliation parameters: $S D$ (livestock density), ncut (mowing frequency).

1060 Figure C.2 Main effects of six key parameters on species survival ratio $S$, from dynamic trees performed on DYNAGraM2 (A) and DYNAGRAM21 (B) outputs. Climate parameters: Tm (temperature), $P m$ (precipitation); soil fertility parameters: $\Phi$ (fertiliser input), $\theta$

1064 frequency). 